\section{CIUDAD SEGREGADA EN ESPAÑA: URBANIZACIONES CERRADAS EN VALENCIA $Y$ SEVILLA}

Arsenio Villar Lama y Miguel García Martín

\section{Resumen}

Las urbanizaciones cerradas son realidades cada vez más recurrentes en el paisaje urbano español. Aunque su atención científica ha estado centrada tradicionalmente en Madrid, este trabajo pretende profundizar en el conocimiento de estas fórmulas de segregación urbana en otros ámbitos de España, concretamente en las aglomeraciones de Valencia y Sevilla. La localización de estas urbanizaciones así como su análisis territorial y tipológico son los principales objetivos de esta investigación. Desde una perspectiva metodológica proponemos la aplicación Street View como base para la localización de estos complejos. Se comprueba que las

\section{URBAN SEGREGATION IN SPAIN: GATED COMMUNITIES IN VALENCIA AND SEVILLE}

Arsenio Villar Lama ${ }^{1}$ and Miguel García Martín ${ }^{2}$

\section{Abstract}

Gated communities are growing throughout the Spanish landscape. While scientific attention has been traditionally focused in Madrid, this paper aims to broaden the depth of knowledge of these formulas of segregation in other areas of Spain, especially in Valencia and Sevilla. The location of these developments, as well as their territorial and typological analysis, are the main goals of this research. From a methodological perspective, Street View has been successfully trialed as the basis to locate these areas. It is ascertained that the gated communities closest to conventional definitions exist with other formulas of enclosure in rural Sevilla and 
urbanizaciones cerradas más ajustadas a las definiciones convencionales conviven con otras fórmulas de cerramiento en el medio rural (Sevilla) y en ámbitos turísticos del litoral (Valencia), cada una con lógicas territoriales propias.

PALABRAS CLAVE: URBANIZACIONES CERRADAS; CERRAMIENTOS URBANOS; AGLOMERACIONES URBANAS; GOOGLE STREET VIEW; ESPAÑA.

Recibido: 25-03-2015

Aceptado: 18-01-2016

1 España. Departamento de Geografía Física y Análisis Geográfico Regional, Facultad de Geografía e Historia Universidad de SeviIla. Correo electrónico: arsenio@us.es

2 España. Departamento de Geografía Humana, Facultad de Geografía e Historia Universidad de Sevilla. Correo electrónico: mgmartin@us.es.

146 revista invi № 86 / Mayo 2016 / Volumen № 31: 145-177 the coastal areas of tourism in Valencia - each with their own territorial logics.

\section{KEYWORDS: GATED COMMUNITIES; URBAN ENCLOSURES; METROPOLITAN AREAS; GOOGLE STREET VIEW; SPAIN.}

Received: 25-03-2015

Accepted: 18-01-2016

1 Spain. Department of Physical Geography and Regional Geographic Analysis, Faculty of Geography and History, University of Seville.Email: arsenio@us.es

2 Spain. Department of Human Geography, Faculty of Geography and History, University of Seville.Email: mgmartin@us.es 
"Si los bienes públicos -los servicios públicos, los espacios públicos, los recursos públicos- se devalúan a ojos de los ciudadanos y son sustituidos por servicios privados pagados al contado, perdemos el sentido de que los intereses y las necesidades comunes deben predominar sobre las preferencias particulares y el beneficio individual. Y una vez que dejamos de valorar más lo público que lo privado, seguramente estamos abocados a no entender por qué hemos de valorar más la ley (el bien público por excelencia) que la fuerza".

Tony Judt, 2010, p. 128.

\section{Introducción y objetivos}

El fenómeno de las comunidades cerradas ha centrado el interés de una parte importante del discurso urbano contemporáneo, en especial desde los enfoques posmodernos, como una forma muy particular de producción y reproducción social del espacio. La proliferación de áreas residenciales privadas y cerradas — primero en Estados Unidos y con posterioridad en el resto de las aglomeraciones urbanas americanas y del resto del planeta- afecta no solo a la morfología de la ciudad sino también a las relaciones y los comportamientos de los ciudadanos, individual y colectivamente. Entre las múltiples implicaciones derivadas de estas tipologías urbanas se pueden subrayar las siguientes: el conflicto entre el espacio público y el privado, la tendencia hacia la segregación física y social de las partes de la ciudad y, especialmente, el miedo como instrumento de configuración urbana.

Por un lado, el espacio público ha sido a menudo entendido como el lugar (físico y social) de las relaciones que dan sentido a las sociedades democráticas modernas, a partir del encuentro espontáneo, el conflicto, la mediación y el contacto con los desconocidos ${ }^{3}$. La privatización de esta función social del espacio público transforma las relaciones que allí se producen, controlándolas y haciéndolas más predecibles, asépticas y superficiales. La sustitución (o simulación) del espacio público por excelencia - la calle- por el recinto privado lleva, en una circunstancia extrema, a reducir el contrato civil a una mera relación comercial entre ciudadanos-clientes ${ }^{4}$.

A su vez, el interés particular de algunos sectores sociales por distinguirse y diferenciarse del resto lleva a éstos a recluirse en barrios y comunidades exclusivas. La búsqueda de un estatus económico, racial o social que refuerce su pertenencia a una élite se ve favorecida dentro de los límites cerrados de una parte de la ciudad, ajena al resto. La cohesión entre individuos y entre ámbitos urbanos se ve comprometida, acentuándose la segregación social y la fragmentación física y territorial ${ }^{5}$.

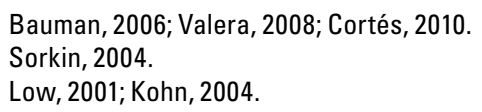

revista invi № 86 / May 2016 / Volume № 31: 145-177 147 
Manteniendo alejado al otro, estos sectores sociales acaban por alejarse de la idea misma de ciudad. ${ }^{6}$

Uno de los ingredientes que motiva la segregación es, precisamente, el miedo. Se trata de un fenómeno psicológico y sociológico entendido como rechazo ante las amenazas que provienen de lo extraño, lo desconocido, lo distinto, lo casual o lo espontáneo (no previsto), circunstancias constitutivas de la condición urbana clásica. El miedo, ya sea individual o colectivo, ha acompañado secularmente a la evolución morfológica de la ciudad ${ }^{7}$. Sin embargo, el urbanismo postmoderno ha acabado por utilizarlo como un recurso para el control y administración del comportamiento urbano, en el momento en que la imagen o representación del miedo ha superado al hecho representado, esto es, a la violencia real y a los fenómenos fácticos de riesgo (delincuencia, crimen, fenómenos naturales, etc.). Es entonces cuando la calle adopta una arquitectura defensiva ${ }^{8}$ a partir del levantamiento de vallas, muros y verjas de separación y la proliferación de formas y funciones segregadoras de los distintos ámbitos urbanos. El fenómeno, que puede extenderse desde un barrio particular a toda la ciudad — como proyecta Davis ${ }^{9}$ para el sintomático caso de Los Ángeles-, acaba por militarizar el espacio urbano mediante el control policial, la

6 Améndola, 2000.

7 Mumford, 1961; Ellin, 1997.

8 Ellin, 1999.

9 Davis, 1990; 2001. limitación de usos y actividades en el espacio público, la vigilancia electrónica (panóptica), el diseño disuasivo de las edificaciones, etc. ${ }^{10}$ Detrás de la instrumentalización del miedo en la configuración de la ciudad pueden detectarse los intereses particulares en el lucro vinculado a las industrias de defensa y seguridad, así como el interés institucional de determinados gestores políticos en mantener la espontánea, azarosa y heterogénea vida urbana bajo control.

A pesar de esta larga trayectoria teórica y conceptual, el fenómeno de las urbanizaciones cerradas ha sido escasamente estudiado en España, a excepción de su capital. El entorno de Madrid ha centrado casi todas las referencias al respecto y se ha convertido en el principal referente español sobre la temática. De la misma forma que ocurre en América Latina, las grandes ciudades han focalizado la primera oleada de literatura al respecto, si bien poco a poco resulta necesario conocer este fenómeno de segregación urbana en ciudades intermedias ${ }^{11}$. De este modo, el presente trabajo pretende seguir avanzando en el conocimiento de estas realidades en España, a través del estudio de los casos de Sevilla y Valencia.

10 Flusty, 1997; Juaristi, 2005.

11 Malizia, 2011. 
La investigación sobre las urbanizaciones cerradas en las aglomeraciones urbanas de Valencia y Sevilla es el propósito general del trabajo, y de él se desprenden los siguientes objetivos. Desde el punto de vista metodológico se afrontará el reto de agilizar la localización de este tipo de urbanizaciones. Bajo una perspectiva territorial pretendemos conocer las dimensiones, características, distribución y variantes de este fenómeno en los ámbitos de estudio y, con relación a otras realidades, procuramos contrastar si existen fórmulas propias de auto-segregación junto a modelos más estandarizados. Sin entrar en profundidad en el análisis jurídico de estas realidades, trataremos de constatar su indefinición jurídica y su traducción en la práctica mediante nuestra experiencia en el trabajo de campo.

La estructura de este trabajo es la siguiente: en primer lugar se ha realizado una revisión general de la literatura sobre las urbanizaciones cerradas, prestando especial atención a los casos de España. En segundo lugar se presenta el ámbito de estudio, las fuentes de información utilizadas y los métodos desarrollados. En tercer lugar se exponen los

ARTíCULO:Ciudad segregada en España: urbanizaciones cerradas en Valencia y Sevilla/ Arsenio Villar Lama y Miguel García Martín principales resultados de la investigación y se contrastan con otros casos. Finalmente se establecen las principales conclusiones y las vías de investigación futura.

\section{Revisión de la literatura}

Las urbanizaciones cerradas se definen como urbanizaciones que restringen el acceso público mediante el uso de puertas, muros y verjas y que suelen emplear personal de seguridad y sistemas de video vigilancia de circuito cerrado ${ }^{12-13}$. La versión española de la definición, propuesta por Canosa ${ }^{14}$, alude a complejos privados, socialmente homogéneos, provistos de servicios y equipamientos exclusivos sufragados por la comunidad de propietarios, dotados de normas de funcionamiento propias y aisladas del exterior mediante muros o verjas perimetrales. Estas definiciones - la primera es quizá la más extendida en este campo- tratan de aglutinar bajo un mismo concepto la diversidad de versiones locales de un fenómeno global. Por su parte, Roitman, añade como requisito la existencia de un marco legislativo preciso, al apuntar que la

12 La revisión epistemológica de las urbanizaciones cerradas y de su trayectoria histórica no es objeto del presente trabajo, aunque algunas obras de referencia sí han sido estudiadas (ver Blackely y Snyder, 1997; Low, 2003; Glasze, Webster y Frantz, 2006; Atkinson y Blandy, 2006).

13 Low, 2003.

14 Canosa, 2002. 
privatización debe estar "avalada por la legislación nacional, provincial y/o local, existiendo además aceptación social de su condición de espacio privado de acceso restringido"15.

Para hablar de urbanizaciones cerradas debe coexistir un cerramiento morfológico-funcional con una auto-segregación social (gated minds) ${ }^{16}$. Por una parte, la segregación se materializa en una serie de elementos físicos que privatizan un espacio usualmente público, siendo ésta la diferencia entre las urbanizaciones cerradas y otras formas de administración privada ${ }^{17-18-19}$. Por otra parte, la esencia de estos complejos está en los acuerdos entre los residentes, en un código de conducta (gate-living), en una responsabilidad colectiva de gestión y en unas cargas internas derivadas. Los servicios colectivos de ocio y consumo sintetizan estas convergencias ${ }^{20}$.

\footnotetext{
15 Roitman, 2004.

16 Brunn, 2006.

17 Algunas urbanizaciones abiertas son ubicadas y diseñadas para que, sin necesidad de utilizar elementos coercitivos, se disuada del acceso público, logrando así una segregación encubierta (zonas de amortiguaciones vegetadas o intersticiales, entrada única, disposición del viario y fondos de saco).

18 Los condominios o complejos de apartamentos vigilados disponen de rigurosas medidas de seguridad y salvaguardan espacios colectivos, pero no incluyen espacios comúnmente públicos, aquéllos que serían de libre acceso sin las puertas o los muros: calles, aceras, parques, lagos, ríos, playas, etc.

19 O’Neill, 1986; Blackely y Snyder, 1997.

20 Atkinson y Blandy, 2006; Bagaeen, 2010.
}

El miedo, el estatus y el carácter de la vivienda como bien de inversión - y no solo de uso- han sido consideradas tradicionalmente como las principales causas a cualquier escala de estudio. Este trabajo, que no tiene como objetivo estudiar con profundidad el peso de estas variables (vid. perspectivas de investigación), sí aborda otros factores que inciden en la distribución del fenómeno a escala local, como las infraestructuras de comunicación o el papel de la administración.

Tal y como se adelantaba en la introducción, las urbanizaciones cerradas han sido catalogadas como "burbujas de seguridad"21 y como ejemplos de "paisajes del miedo"22. De hecho, el miedo se ha convertido en un ítem estratégico para los promotores de estos complejos, especialmente en aquellos países donde las fuerzas del orden público no aseguran un nivel básico de seguridad ${ }^{23}$. Por su parte, el estatus es entendido como una búsqueda

\footnotetext{
21 Atkinson y Blandy, 2006.

22 Brunn, 2006; Frantz, 2006.

23 Vidal Kooppmann, 2001; Thuiliier, 2007; Roitman y Giglio, 2010; Bagaeen, 2010.
} 
de diferenciación económica, social y ambiental. Según Le Goix ${ }^{24}$, este último se materializa en la protección frente a los tradicionales problemas del medio ambiente urbano (tráfico, áreas degradadas, equipamientos gratuitos y masificados, usos del suelo indeseables...). Finalmente, el carácter de la vivienda como bien de inversión y protección se resume en la idea de que el carácter endótropo de estos complejos lo aíslan de los problemas del entorno y, por tanto, de su posible desvalorización urbana y residencial (disinvestment) ${ }^{25}$. Baegeen ${ }^{26}$ resume los tres ingredientes generales en las tres "p" -peace, prestige \& perfect vistas-, resaltando así la protección frente a lo externo, la importancia de la promoción de unos estilos de vida diferenciados y, finalmente, la relevancia del paisaje como producto inmobiliario y como marca diferenciada para las élites.

Entre los factores locales suele incidirse en el desarrollo de la tecnología y, particularmente, de las comunicaciones. La búsqueda de grandes bolsas de suelo suele llevar a estos productos inmobiliarios a una localización periférica, que se compensa con su proximidad a las principales arterias de comunicación y, por ende, a la ciudad central. Este factor ha sido crucial, por ejemplo, para explicar el

24 Le Goix, 2007.

25 Le Goix, 2007; Prada, 2011.

26 Bagaeen, 2010. espectacular incremento y la ubicación de los countries en el Área Metropolitana de Buenos Aires ${ }^{27}$. La administración pública juega un papel esencial para entender la extensión del fenómeno, ya que los gobiernos locales, ante el vacío jurídico al respecto y en función de la naturaleza de sus propios territorios, pueden favorecer la creación de estos complejos como modo de externalizar la prestación de algunos servicios ${ }^{28}$.

Si bien este paradigma académico que viene teorizando sobre el fenómeno de las urbanizaciones cerradas se basa en una interpretación muy crítica de sus factores causales, así como de sus consecuencias sociales y territoriales, no es menos cierto que tras esta corriente subyacen algunos convencionalismos $^{29}$. Precisamente, Uduku y Bagaeen ${ }^{30}$ procuran superarlos aportando incluso una visión benigna del tema: la autonomía en la gestión de los servicios como mecanismo de sostenibilidad; la incorporación de criterios constructivos "compactos" en las nuevas promociones que favorecen la densificación edificatoria; y el fortalecimiento de los lazos sociales y de los sentimientos de pertenencia dentro de un colectivo (argumento que también sostiene Boall ${ }^{31}$ ).

\footnotetext{
27 Vidal Kooppmann, 2001; Roitman y Giglio, 2010.

28 Canosa, 2002; 2007; Prada, 2011.

29 Salcedo, 2005.

30 Bagaeen, 2010.

31 Boal, 2001.
} 
Las urbanizaciones cerradas conforman hoy un fenómeno global que se reproduce localmente con mayor o menor intensidad. Norteamérica (Estados Unidos y Canadá), Latinoamérica (Argentina, México, Chile, Brasil), Próximo y Medio Oriente (Jordania, Israel, Dubái), Sudáfrica y China son - a tenor de la bibliografía consultada- las áreas del planeta donde este fenómeno alcanza sus mayores dimensiones. En general, todos los autores coinciden en el aumento de la polarización social como detonante de la expansión del fenómeno. En Europa, donde la desigualdad interna parece ser inferior al resto de continentes, los siguientes países presentan valores relativamente altos de desigualdad ${ }^{32}$ y una creciente atención científica sobre la proliferación de urbanizaciones cerradas: Turquía ${ }^{33}$, algunos países excomunistas como Bulgaria ${ }^{34} \mathrm{O}$ Polonia $a^{35}$, el Reino Unido ${ }^{36}$, Portugal y España ${ }^{37}$.

Aunque las referencias sobre el fenómeno en España son escasas, su estudio es esencial para contextualizar esta investigación. En este sentido destacan fundamentalmente los trabajos de Wehrhahn y Raposo $^{38}$ para los casos de Madrid y Lisboa;

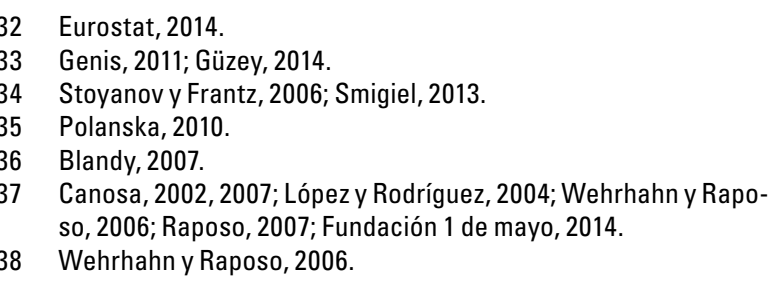

152 revista invi № 86 / Mayo 2016 / Volumen № 31: 145-177
Blanquer $^{39}$, bajo una perspectiva jurídica y aplicada a los espacios turísticos; y Canosa ${ }^{40}$, que ofrece un panorama completo del fenómeno en el área de Madrid.

Por último, otro de los retos de este trabajo, de carácter metodológico, es agilizar la localización de las urbanizaciones cerradas en cualquier territorio. Muchos autores han reconocido en sus investigaciones que la cuantificación y el análisis de la distribución de este tipo de urbanizaciones - desde la escala global a la local- tiene una importante debilidad en la ausencia de estadísticas al respecto, ya que no suelen ser identificadas de forma específica en los registros pertinentes ${ }^{41}$. Esta investigación trata de solventar dicha debilidad.

\author{
2002 \\ 40 Canosa, 2002; 2007. \\ 41 Jürgens y Gnad, 2002; Polanska, 2010; Roitman y Giglio, 2010.
}




\section{Ámbito de estudio, fuentes y métodos}

\section{ÁMBITO DE ESTUDIO}

Valencia y Sevilla, en ese orden, se sitúan en un segundo nivel en la jerarquía del sistema de ciudades metropolitanas de España, tras Madrid y Barcelona. Estas aglomeraciones hospedan y movilizan en torno a 1,5 y 1,3 millones de habitantes respectivamente. La definición de los ámbitos de estudio se corresponde con una delimitación propia que toma como base el trabajo de Feria Toribio ${ }^{42}$ sobre movilidad residencia-trabajo en las áreas metropolitanas españolas ${ }^{43}$.

El Área Metropolitana de Valencia se sitúa en el extremo oriental de la península Ibérica en torno a una ciudad central que posee 799.188 habitan$\operatorname{tes}^{44}$ y que representa algo más de la mitad de la población del conjunto metropolitano (figura 1). La huerta circundante y la albufera, el río Turia y el mar Mediterráneo han sido los condicionantes territoriales más importantes en el proceso de construcción metropolitana. Este proceso se ha

\footnotetext{
42 Feria Toribio, 2008.

43 A los municipios centrales definidos por el trabajo referido se han agregado otros limítrofes o próximos cuando han sido localizadas urbanizaciones cerradas en ellos (p.e. Cullera y Alberic en Valencia y Aznalcázar en Sevilla).

44
}

traducido en la desaparición generalizada de la huerta valenciana a través de la expansión residencial de capital privado y en el desarrollo de grandes proyectos promovidos por la administración para la difusión mediática y turística de la urbe.

El Área Metropolitana de Sevilla se sitúa en el suroeste de la España peninsular (figura 1). Sevilla es uno de los 46 municipios que conforma la aglomeración y aglutina en torno a la mitad de su población con 700.169 habitantes $^{45}$. La construcción metropolitana de Sevilla tiene su punto de inflexión en la Exposición Universal de 1992. El crecimiento económico observado desde los años ochenta, unido a las inversiones públicas vinculadas a este evento, se traducen en una extensión del territorio metropolitano al margen de la tendencia demográfica. A su vez, se manifiesta en la adopción del modelo de ciudad difusa de baja densidad donde ya se observan, según algunos autores, casos de complejos urbanos cerrados ${ }^{46}$.

\section{Fuentes y métodos}

La cuantificación y el análisis de la distribución de este tipo de urbanizaciones — desde la escala global a la local — tienen una importante debilidad

\footnotetext{
45 Instituto Nacional de Estadística, 2011.

46 Caravaca y García, 2009; Delgado y García, 2009.
} 


\section{FIGURA 1. MAPA DE LOCALIZACIÓN DE LAS ÁREAS METROPOLITANAS DE VALENCIA Y SEVILLA.}

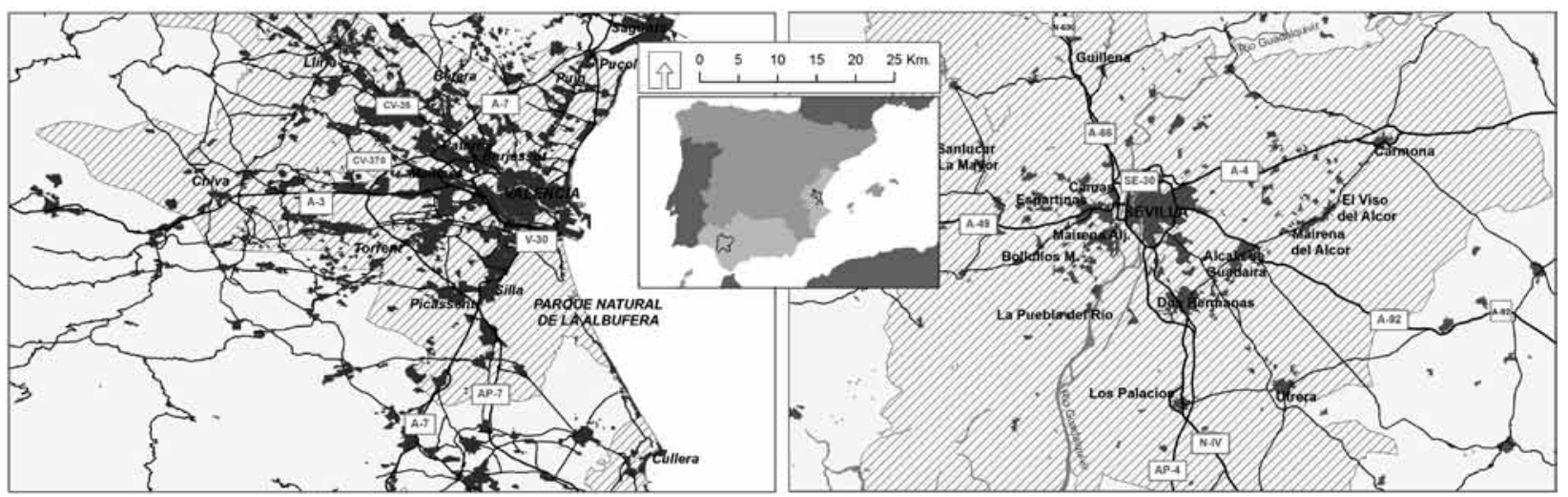

Fuente: elaboración propia.

en la ausencia de estadísticas al respecto, ya que, como detallan Roitman y Giglio ${ }^{47}$, no suelen ser registradas de forma específica en los censos u otras fuentes oficiales. A nivel internacional, el número de publicaciones científicas puede orientarnos sobre la intensidad del fenómeno, pero apenas ayuda a localizar estos complejos en el territorio para un análisis más detallado. A escala local persiste esa falta

47 Roitman y Giglio, 2010. de control institucional, estadístico y cartográfico, siendo patente en nuestros ámbitos de estudio.

Esta debilidad se ha superado mediante una metodología específica. La aplicación on-line Street View (Google Maps) permite recorrer el viario fotográficamente $e^{48}$. La herramienta está disponible para todas las calles y carreteras que han sido recorridas por el vehículo que, en su día, capturó

48 Google tiene fotografiado el viario de los siguientes países: Bélgica, Bulgaria, Croacia, Dinamarca, Eslovaquia, Eslovenia, España, Estonia, Finlandia, Francia, Hungría, Irlanda, Italia, Letonia, Lituania, Noruega, Países Bajos, Polonia, Portugal, Reino Unido, República Checa, Rumania y Suecia en Europa; Brasil, Canadá, Chile, Colombia, Estados Unidos, México y Perú en América; Australia, Japón, Tailandia, Taiwán y Nueza Zelanda en AsiaPacífico; Botswana, Lesotho y Sudáfrica en África. 


\section{FIGURA 2. FASES Y MÉTODOS DE LA INVESTIGACIÓN.}

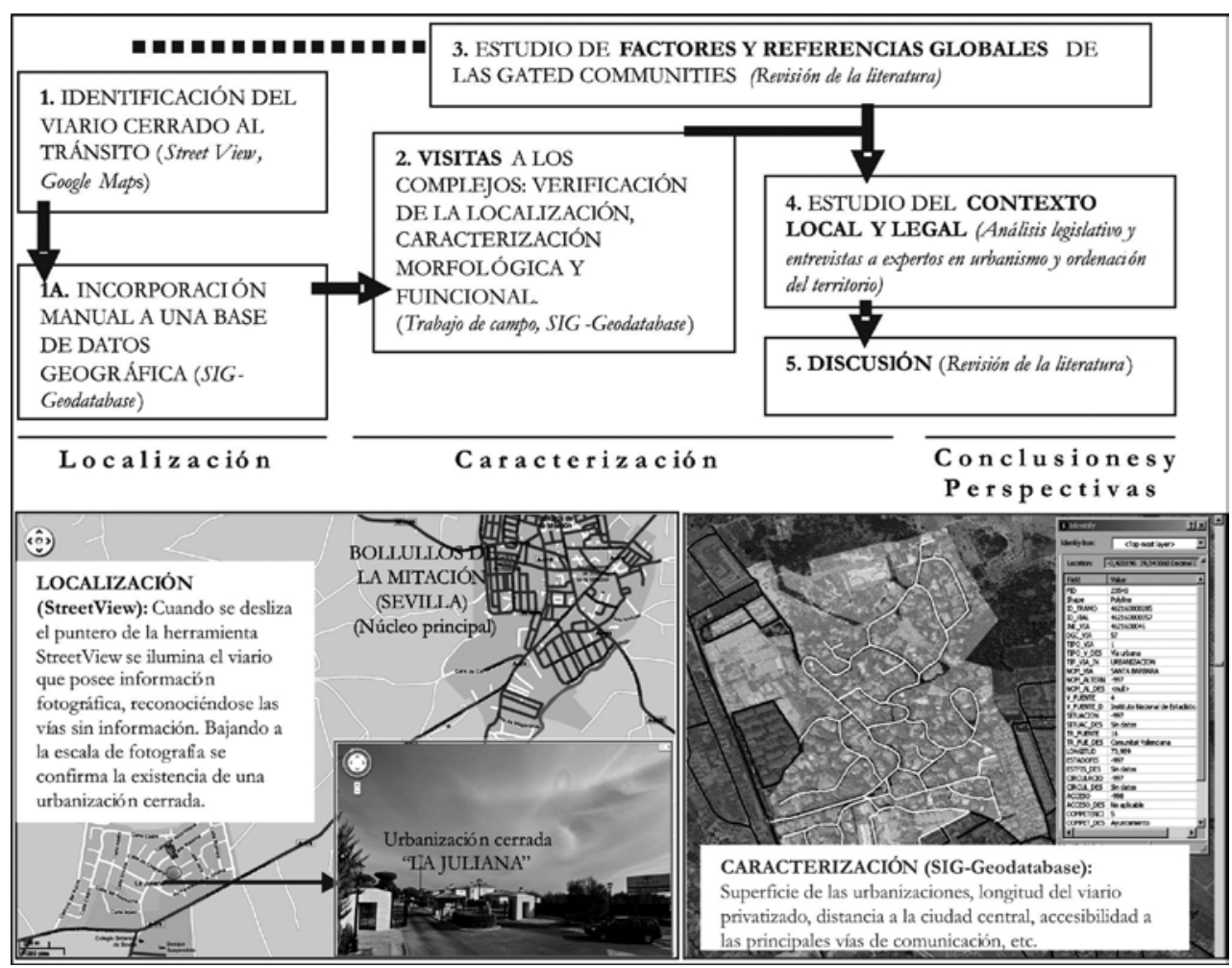

Fuente: elaboración propia.

las instantáneas. Teniendo en cuenta la titularidad pública del viario español, parece lógico pensar que todas las calles serían fotografiadas. Sin embargo, existen vías sin datos donde no se capturaron fotografías. La ausencia de datos responde fundamentalmente a cuatro razones:
- Caminos de tierra, que no fueron recorridos por el vehículo de Google Street View y, al parecer, se descartaron de la base de datos;

- Calles de urbanizaciones en construcción, inaccesibles en aquel momento para el coche; 
- Vías peatonales;

- Viario de urbanizaciones cerradas, donde el control de acceso desalentó o prohibió la entrada al vehículo.

En un primer momento se solicita a Google la información vectorial de todo el viario sin datos. Se buscaba agilizar la búsqueda y — tras la criba de descartar caminos rurales, áreas en construcción y calles peatonales - desarrollar una base de datos espacial sobre la localización de las urbanizaciones cerradas para el conjunto de España (especialmente sus aglomeraciones urbanas y el litoral). Sin embargo, ante la falta de colaboración de la empresa se decide realizar de forma manual, acotando el análisis a dos ámbitos representativos que no tuvieran estudios al respecto y que complementaran el ya investigado caso de Madrid. Una vez seleccionados los casos de Valencia y Sevilla se identifican en ellos los conjuntos urbanos donde la ausencia de datos se corresponde con urbanizaciones cerradas. La integración de los complejos en un Sistema de Información Geográfica (SIG) —donde cada caso posee unos atributos asociados y una localización en relación a otros elementos del territorio— facilita posteriormente la extracción de variables espaciales y una lectura más completa del fenómeno (figura 2).

La detección mediante Street View ha agilizado enormemente la preparación del trabajo de campo, esencial para establecer patrones generales, tipologías y particularidades. Se han visitado todos los cerramientos urbanos detectados. Este trabajo de campo tiene 3 partes: la experiencia propia de intentar entrar en el complejo; la entrevista con los administradores, los conserjes o los miembros de la seguridad privada; y, finalmente, el inventario visual de las características de la urbanización, especialmente los elementos de seguridad y/o segregación (límites, símbolos, barreras, vigilancia).

Como trabajo de gabinete, aparte de la revisión de la literatura al respecto, se ha realizado un análisis de la legislación urbanística. La complejidad jurídica del fenómeno ha conducido a complementar el estudio legal con un sistema de entrevistas a expertos seleccionados ${ }^{49}$. Adicionalmente se han hecho consultas puntuales al planeamiento para conocer la situación de algunos complejos y de sus viarios en la zonificación urbanística.

49 Se trata de los siguientes expertos: Juan Antonio Morales, presidente de la Asociación de Defensa del Territorio del Aljarafe; Jorge Benavides, arquitecto; Gustavo Contreras, geógrafo; Luis Zambrana, economista; Manuel Benavent, geógrafo consultor; y, finalmente, Manuel Burraco y Esteban Castelví, expertos del Área de Urbanismo de la Consejería de Obras Públicas y Vivienda (Junta de Andalucía). 


\section{Resultados}

\section{(IN)DEFINICIÓN JURÍDICA}

Las urbanizaciones cerradas en España "son una realidad inmobiliaria que desde el punto de vista del Derecho sugiere más interrogantes que respuestas jurídicamente seguras" ${ }^{50}$. Aparecen con la Ley del Suelo de 1956, al amparo de la privatización de una parte de la actividad urbanizadora: "El carácter privado se prolongaba más allá del proceso de promoción si existían elementos y servicios privados de uso colectivo, junto con una organización propia para la conservación del conjunto"51.

En España, la figura jurídica sobre la cual se ha basado buena parte de los cerramientos es la Entidad Urbanística de Conservación ${ }^{52}$. Aunque tiene su origen en la Ley del Suelo de 1956, se consolida como tal en el Reglamento de Gestión Urbanística de 1978, siendo posteriormente desarrollada autonómicamente. La Entidad, acordada con el Ayuntamiento e inscrita en el Registro de la Propiedad, permite la conservación y la gestión propia del conjunto pero, y esto es lo más controvertido, no

50 Blanquer, 2002, p. 849.

51 Arroyo, 1999, p. 5.

52 Mientras en la Comunidad de Propietarios se comparte y se es copropietario de un elemento privado común, en la Entidad de Conservación se está obligado a conservar y mantener espacios, redes y equipamientos de titularidad pública. El segundo coexiste con el primero cuando hay elementos comunes privados. clarifica si es posible impedir, o controlar, el acceso al tránsito general.

Según la normativa, el convenio urbanístico de un proyecto de nueva planta no se traduce necesariamente en la cesión de viales u otros espacios internos (que pasarían a ser bienes demaniales), sino que puede satisfacerse en dinero o en la permutación por otros terrenos. Este es el caso del "complejo inmobiliario" que recoge la Ley de Propiedad Horizontal, identificado en varias ocasiones en este estudio. Algunas urbanizaciones ya consolidadas — que no cumplieron con sus cesiones en el momento correspondiente-, para mantener el estatus privado de sus calles, han llegado a semejantes acuerdos. En determinadas investigaciones ya se advierte que, generalmente, las urbanizaciones mantienen su condición de cerradas, o casi cerradas, mediante acuerdos verbales con las corporaciones locales. Por lo tanto, el cerramiento es una concesión de los ayuntamientos ${ }^{53}$.

Por otro lado, hemos observado que un buen número de cerramientos se produce en el medio rural en urbanizaciones que están fuera de la ordenación urbanística. En tales casos, especialmente

53 Canosa, 2002. 
numerosos en el ámbito de Sevilla, el ayuntamiento no contempla la prestación de los servicios básicos (recogida de basura, limpieza de calles y jardines, pavimentación, alumbrado...). En consecuencia, los vecinos deciden cerrar la entrada al complejo. La propia indefinición de estos conjuntos de viviendas explica la alegalidad del cierre ("nuestras calles, nuestras puertas").

Teniendo en cuenta que las comunidades cerradas en España no poseen una normativa específica, sino que son el resultado bien de la praxis urbanística, bien de la ausencia de planeamiento, el análisis jurídico de estas realidades exigiría un profundo estudio de la jurisprudencia. El presente trabajo no tiene como objetivo un análisis normativo de este fenómeno sino la constatación de su indefinición en la práctica. Así se ha comprobado claramente durante el trabajo de campo, tanto en los elementos del cerramiento como en la experiencia propia para acceder a los complejos $^{54}$.

Hemos podido comprobar que la segregación de estas realidades urbanas se materializa tanto en la permeabilidad de acceso como en su grado de autonomía en la gestión de los servicios municipales.

54 En muchos casos los vigilantes argumentaban que no podían interrumpirnos el paso pero que sí se sentían autorizados para controlar a quién entra y sale del recinto. En Tancat el Alter (Valencia), el vigilante, después de mostrarse dubitativo ante nuestro ingreso en la urbanización, nos siguió en casi todo momento en nuestro recorrido por el complejo.
Según hemos verificado, los ayuntamientos asumen una parte de los servicios básicos. Sin embargo, en muchos casos, el carácter remoto de la urbanización y la voluntad de sus vecinos de mejorarlos conduce a la contratación de personal específico para la limpieza, la jardinería e, incluso, la retirada de la basura (p. ej. Urbanización Santa Bárbara). El sobrecoste (doble tasación) que supone mantener estos espacios bajo unos estándares de calidad superiores al resto del espacio público, unido a la protección de las inversiones privadas en los inmuebles, explicaría el cerramiento. En síntesis, subyace un interés mutuo: los propietarios ganan independencia y privacidad y el ayuntamiento delega en éstos algunas obligaciones públicas de competencia municipal.

\section{Distribución y tipología}

En esta investigación se han identificado un total de 71 urbanizaciones cerradas y otras fórmulas de cerramiento repartidas en las dos áreas de estudio. Su distribución espacial y sus principales características quedan recogidas en los mapas de las figuras 3 y 5 , así como en la tabla del anexo. 


\section{FIGURA 3. LOCALIZACIÓN DE LOS CERRAMIENTOS URBANOS EN LA AGLOMERACIÓN URBANA DE SEVILLA}

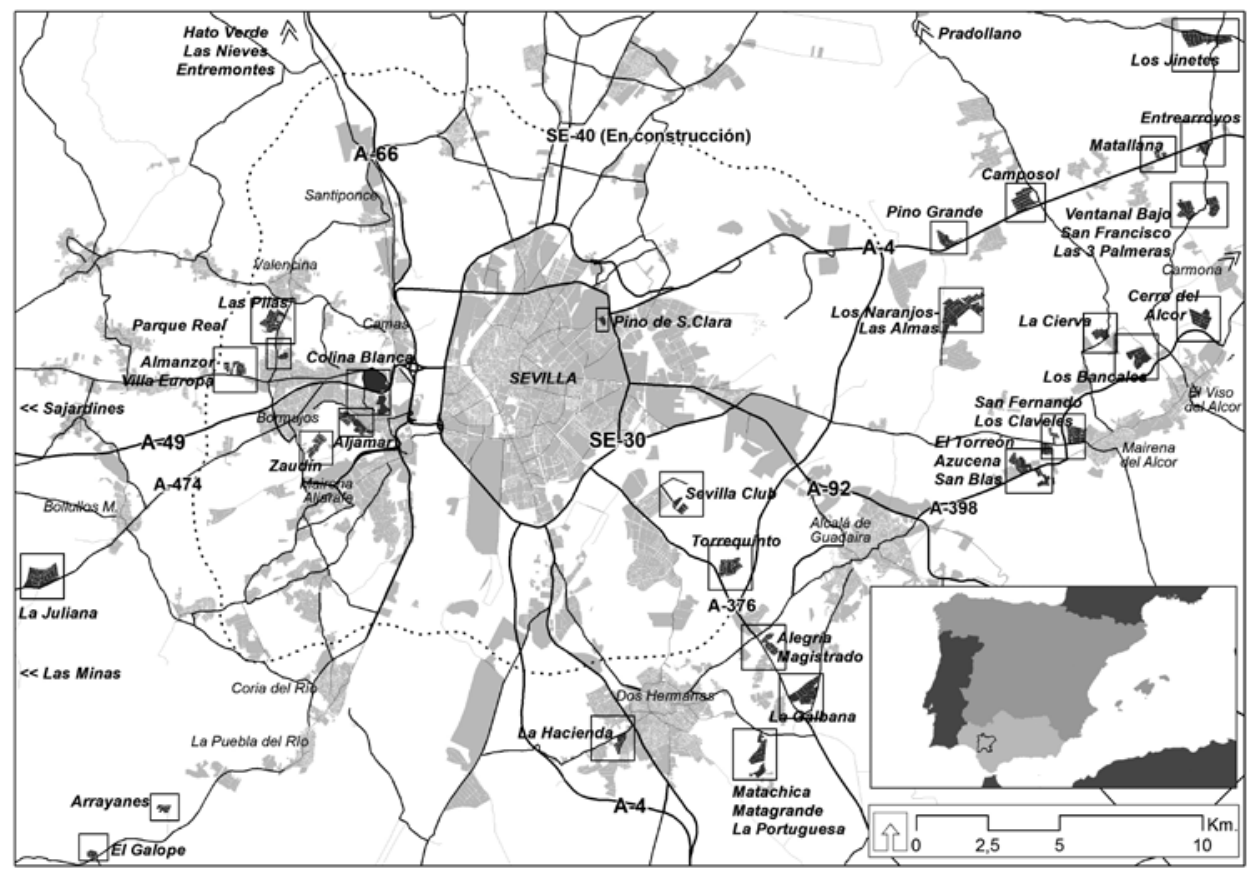

Fuente: Elaboración propia.

A su vez, hemos clasificado las fórmulas de segregación urbana en tres tipos principales: indicativas, que desalientan el acceso mediante el uso de señalética de restricción de paso; de control, donde existe una garita y una barrera de paso con vigilancia (conserje o empresa de seguridad); y de restricción total de acceso, donde, a diferencia del anterior, se prohíbe la entrada categóricamente. Con ello se pretende evaluar el menor o mayor nivel de oclusión de estos espacios urbanos, que no responden a una clasificación dicotómica (abierto/cerrado) sino a una tendencia gradual.

La distribución de esta tipología en las áreas de estudio tiene un importante factor explicativo en los diferentes entornos metropolitanos encontrados: suburbano, rural y litoral-turístico. Por entorno suburbano se entiende la expansión residencial difusa del espacio "circumperiférico" de los 
núcleos metropolitanos; el segundo caso se ajusta a la definición de lo "rururbano", una mezcla de elementos del paisaje rural (parcelamiento agrario, huertas, casas de labranza) y otros generados por la urbanización (nuevas viviendas para activos no agrarios) $)^{55}$; y el tercero alude a espacios orientados a las funciones residenciales y terciarias vinculadas al turismo litoral.

En la aglomeración urbana de Sevilla se ha contabilizado un total de 54 cerramientos urbanos (figura 3). Su área total (1.130 ha) supone el 7,3\% de toda la superficie urbana metropolitana y el 21,6\% del uso de suelo urbanizaciones y diseminado. El viario "cerrado" representa en torno al 4,4\% de toda la red metropolitana. Por su parte, se contabilizan en torno a 7.900 viviendas que suponen un 1,3\% del parque inmobiliario residencial. En el sector de Los Alcores (Carmona, El Viso, Mairena y Alcalá) este porcentaje alcanza el 8\% (PIE) ${ }^{56}$. De ellos, 27 complejos se integran en entornos suburbanos, próximos a importantes vías de comunicación, con habitantes de un perfil social homogéneo medioalto, unos servicios y equipamientos colectivos (lúdicos y deportivos), club social, una gestión

\section{Grupo Aduar, 2000}

56 Estos cálculos se han realizado partiendo de las siguientes fuentes: el Censo de Población y Vivienda de 2011 (Instituto Nacional de Estadística), la red viaria del proyecto Cartociudad de 2006-2014 (Instituto Geográfico Nacional), los Datos Espaciales de Andalucía para escalas intermedias de 2009 (Instituto de Estadística y Cartografía de Andalucía) y la cartografía básica del Catastro (Dirección General del Catastro). propia, buenos estándares urbanísticos, baja densidad edificatoria y, finalmente, un elenco de elementos de seguridad que prohíben (o desalientan) la entrada al recinto. Estas urbanizaciones tienen, por norma general, un grado elevado de restricción de acceso, debido a un rígido control de seguridad y/o a mecanismos de cierre automático de las puertas de entrada (urbs. Colina Blanca, Las Canteras, Torrequinto, La Juliana, La Cierva). En algunos casos, sin embargo, el control es más laxo contando, simplemente, con restricciones indicativas (por ejemplo urbs. Los Sajardines, Balcón de los Alcores, etc.).

En Sevilla, los complejos anteriores coexisten con cerramientos localizados en entornos rurales y vinculados a urbanizaciones fuera de la ordenación urbanística (27 casos). Se sitúan al calor de carreteras secundarias y presentan calidades constructivas intermedias, tanto en el acondicionamiento de los espacios colectivos (viarios, pavimentación, alumbrado...) como en el espacio residencial, donde la vivienda suele ir acompañada de jardín o parcela rústica. No existe un único patrón edilicio, el perfil de sus habitantes es más heterogéneo (y en 
FIGURA 4. TIPOLOGÍA DE CERRAMIENTOS URBANOS EN LOS ÁMBITOS DE ESTUDIO.

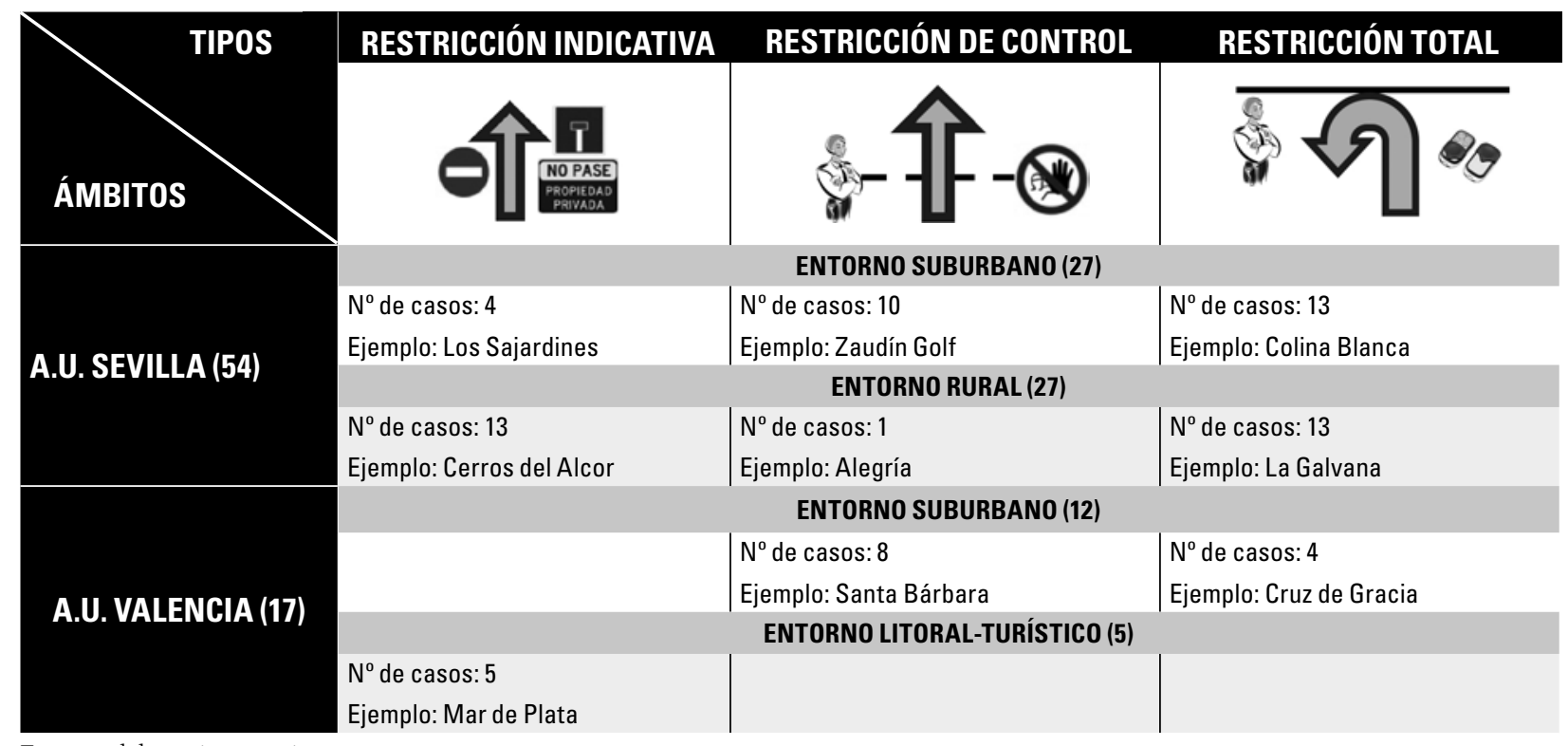

Fuente: elaboración propia.

conjunto más bajo que en el entorno suburbano) y no hay club social —sólo junta de propietarios-. El cerramiento, en función de los artefactos de seguridad observados, tiene un carácter distinto: la ausencia de personal de vigilancia ("muy costoso para los vecinos") se compensa a veces con mecanismos para la apertura y cierre automático de las puertas (Urbs. Matagrande, Los Bancales, Las Nieves, Entremontes...). Este hecho endurece el acceso al interior de la urbanización aunque, como se

ARTíCULO:Ciudad segregada en España: urbanizaciones cerradas en Valencia y Sevilla/ Arsenio Villar Lama y Miguel García Martín ha comprobado en el trabajo de campo, muchas de ellas permanecen abiertas durante el día. Y es que durante la noche, como atestiguan sus vecinos, se sienten "inseguros y desatendidos en medio del campo".

Debe señalarse que muchas de estas urbanizaciones en el medio rural se sitúan en los límites de grandes términos municipales (Carmona, Alcalá de Guadaira) muy próximos a otros núcleos de población. Este hecho facilita el acuerdo entre el

revista invi № 86 / May 2016 / Volume № 31: 145-177 161 


\section{FIGURA 5. LOCALIZACIONES DE LOS CERRAMIENTOS URBANOS EN LA AGLOMERACIÓN URBANA DE VALENCIA}

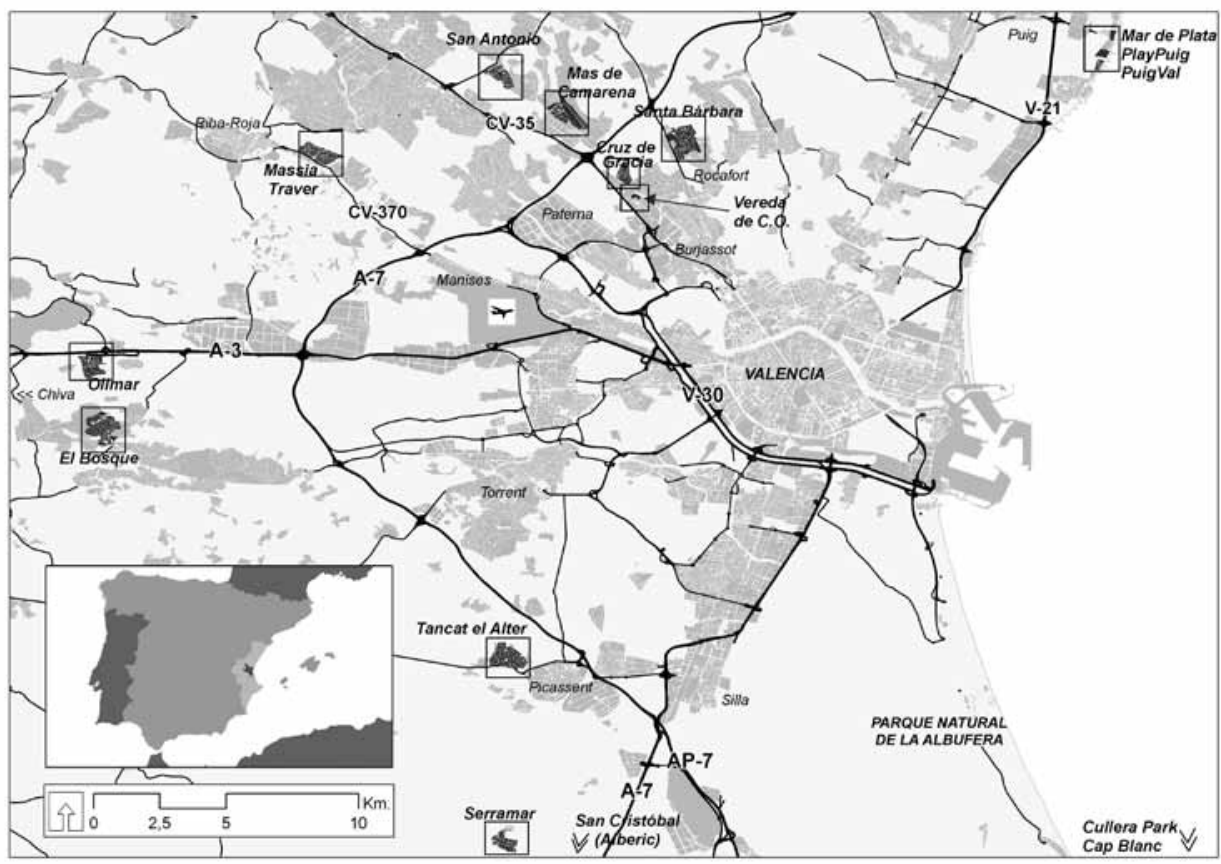

Fuente: elaboración propia.

ayuntamiento y la asociación de vecinos para la autogestión de determinados servicios y la privatización en la práctica de "sus calles".

En la aglomeración urbana de Valencia se contabilizan un total de 17 cerramientos urbanos (figura 5). Su área total (520 ha) supone el 2,3\% de toda la superficie urbana y sus calles representan el 1,8 $\%$ de todo el viario metropolitano. Por su parte, el número de viviendas contabilizadas, en torno a 4.700 , constituye el 0,5\% del total del parque inmobiliario residencial.

A su vez, 12 urbanizaciones se sitúan en entornos suburbanos. Dentro de este conjunto destacan las urbanizaciones de mayor lujo y sus mecanismos casi militares de protección: lector de matrículas, puertas corredizas, cámaras por todo el viario, 
petición de documentación a la entrada o turnos de vigilancia constante por toda la urbanización (urbs. El Bosque, Cruz de Gracia, Santa Bárbara y Tancat El Alter).

En Valencia no se han observado casos equiparables al de la capital andaluza con complejos cerrados en el medio rural (el único caso similar podría ser la urbanización San Cristóbal en Alberic). Sin embargo, debido a su proximidad al mar, se han detectado complejos cerrados de carácter litoral y turístico, con lógicas distintas a las urbanizaciones cerradas al uso. Estas urbanizaciones (5 casos) poseen un nivel de segregación urbana inferior a los complejos suburbanos, ya que se basan en una variada e intensa señalética de restricción de acceso (arcos de entrada para diferenciarse del resto del viario, señales de vigilancia y de propiedad particular, etc.) pero no poseen puertas o garita de vigilancia. Esto se debe, en parte, a la elevada estacionalidad de los residentes y al consecuente uso vacacional de los inmuebles como segunda vivienda. La principal diferencia entre los complejos de Puig (urbs. Playpuig, Puig-Val y Mar de Plata) y de Cullera (urbs. Cap Blanc y Cullera Park) es que los primeros son más pequeños y poseen un formato de edificación plurifamiliar y en altura, mientras que los segundos son más extensivos (vivienda unifamiliar exenta) y guardan una mayor similitud morfológica con las urbanizaciones cerradas al uso. Según sus administradores, las urbanizaciones de Cullera están inmersas en sendos procesos de recepción municipal debido al elevado coste de los servicios para los propietarios. En la urbanización Cap Blanc, donde es notorio el estado de abandono de sus espacios colectivos, uno de sus sectores ha llegado a emanciparse del resto, poniendo puertas de acceso y asumiendo sobrecostes de mantenimiento.

Tanto en Sevilla como en Valencia, dentro de los entornos suburbanos, constatamos la existencia de una morfología particular. Se trata de pequeños conjuntos inmobiliarios cerrados con una densidad edificatoria sensiblemente superior (pequeños bloques de apartamentos y viviendas adosadas) y un nivel de restricción muy alto. Se han identificado 4 casos en Sevilla y 3 en Valencia. De ellos, Aljamar (Tomares, Sevilla) y Mas de Camarena (Bétera, Valencia) son casos peculiares: macrourbanizaciones abiertas donde se cedieron los viales estructurantes y principales dotaciones públicas, dejando como privado el viario interno de cada sector residencial. 
FIGURA 6. EJEMPLOS FOTOGRÁFICOS DE LA TIPOLOGÍA DE CERRAMIENTOS URBANOS EN LOS ÁMBITOS DE ESTUDIO.
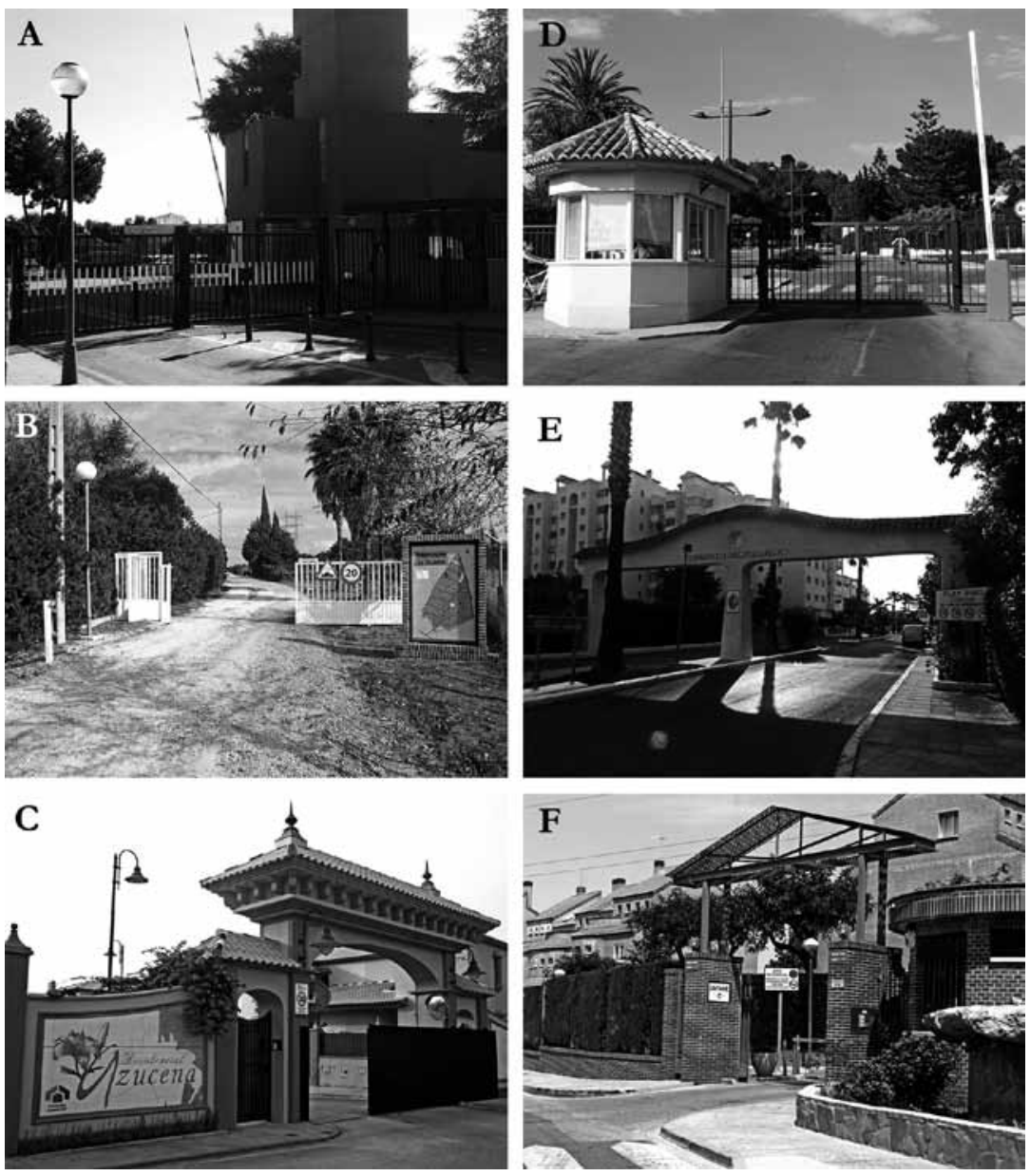

Entorno suburbano: Colina Blanca (A) y Cruz de Gracia (B). Entorno rural: La Galvana (C). Entorno litoral: Play-Puig (D). Pequeños complejos de alta densidad: Aljamar (E) y Mas de Camarena (F). Fotografías: los autores. 


\section{Elementos disuasivos de la segregación urbana}

El hecho de que nos autorizaran la entrada en la mayoría de las ocasiones confirmó la idea de que en España prevalece la urbanización pseudo-cerrada, es decir, aquella donde el personal de seguridad, las puertas y los puntos de acceso son simbólicos, las calles y equipamientos son públicos pero las señales, las barreras y el personal sugieren una atmósfera privada dentro del complejo ${ }^{57}$. Efectivamente, en nuestras visitas a las urbanizaciones más lujosas (p. ej. urbs. El Bosque y Santa Bárbara en Valencia) reconocían que no pueden negar el paso, pero que la simbología y el control desalientan a menudo el tránsito general.

Estos complejos pseudo-cerrados se apoyan en una serie de elementos disuasorios que inhiben el acceso. Los primeros, de carácter más básico, son el emplazamiento remoto y el carácter endótropo de su viario (un único punto de entrada y salida). $\mathrm{Y}$ es que, al margen de su grado de permeabilidad, el hecho de estar alejados de las rutas a pie y de conformar un "culo de saco" para el viandante o el conductor aseguran prácticamente su aislamiento.

57 Wehrhahn, 2003; Wehrhahn y Raposo, 2006.
A esto se le une a veces el reducido tamaño de algunos complejos, donde es fácil identificar al extraño.

A partir de estos condicionantes encontramos otros elementos disuasivos como la simbología, las puertas o barreras, los muros o verjas y el personal de seguridad (figura 7). Normalmente son más ornamentales que efectivos, ya que se trata de una puerta de entrada (a veces abierta de día y cerrada de noche) y algunos símbolos de restricción de paso que suelen completar el mensaje ("Urbanización privada", "Prohibida la entrada", "Calle sin salida”...). La seguridad privada y las cámaras de seguridad se restringen a las comunidades más lujosas incluyendo, en el caso de Valencia, lectores de matrícula ${ }^{58}$. Por lo general no existe un perímetro como tal, sino que son las verjas de las viviendas situadas en el contorno las que actúan como límite.

58 En nuestra visita a Cruz de Gracia, la única urbanización de Valencia que nos prohibió tajantemente el acceso, comprobamos, durante nuestra entrevista, que el empleado de seguridad apuntaba, manualmente, las matrículas de todos los vehículos que accedían al complejo. 

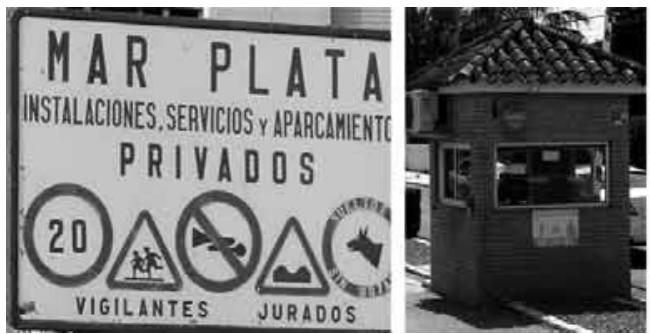
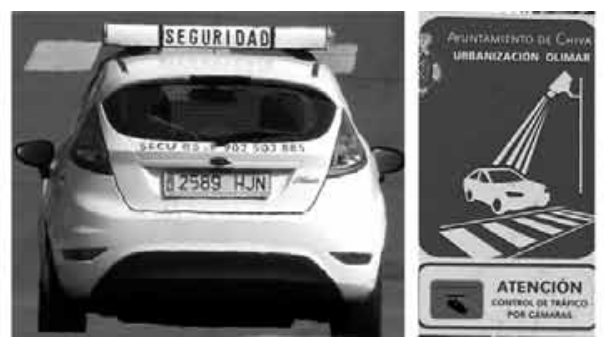

Fotografías: los autores.

Sin embargo, los ámbitos de estudio presentan algunas urbanizaciones con elementos de segregación mucho más potentes que sí recuerdan la "militarización" del espacio ${ }^{59}$. En ellas, el personal de seguridad presenta una actitud casi marcial, la entrada está efectivamente video-vigilada, las puertas son corredizas y, además, el paso peatonal está condicionado a veces a la apertura del paso para vehículos. El perímetro lo dibujan muros y vallas con elementos punzantes como trozos de cristal o alambrados.

\section{Discusión, conclusiones y perspectivas de investigación}

Desde el punto de vista metodológico se ha comprobado la dificultad para localizar las urbanizaciones cerradas y cartografiarlas, debido a su

59 Davis, 1990. indeterminación jurídica. Siendo esta tarea de suma importancia en su análisis territorial, entendemos que este artículo hace una aportación metodológica que consideramos relevante por dos motivos. Primero, porque agiliza notablemente la localización de estos complejos y, en consecuencia, la preparación y la realización del trabajo de campo. Concretamente, se dedicaron solo 2 jornadas de trabajo a la localización previa de los cerramientos en cada aglomeración urbana. El trabajo de campo demostró la efectividad del método, ya que, de un lado, se confirmaron todos los cerramientos y, de otro, solo se descubrieron 2 cerramientos inéditos. En segundo lugar porque, para futuros estudios comparativos o como estímulo para otros investigadores, es posible aplicar el método en cualquier parte de España y en muchos países del mundo recorridos por Street View. 
En las aglomeraciones urbanas de Sevilla y Valencia se han contabilizado un total de 54 y 17 cerramientos urbanos (1.130 ha y 7.900 viviendas en Sevilla, 520 ha y 4.700 viviendas en Valencia). Estas cifras esconden una notable diversidad morfológica y funcional, incluyendo desde complejos próximos al concepto estandarizado de urbanización cerrada a otras versiones de cerramiento con sus propias lógicas territoriales. Así, si nos atenemos a la noción de gated community (entorno suburbano, restricción total o de control, baja densidad edificatoria...), se identificarían 27 y 12 casos respectivamente. Estas cifras permiten contrastar, a grandes rasgos, las dimensiones del fenómeno en nuestros ámbitos de estudio en relación a otras áreas de referencia.

En la periferia de Madrid, Canosa ${ }^{60}$ reconoce 21 urbanizaciones cerradas que ocupan unas 2.500 hectáreas y aglutinan a unas 7.800 viviendas, lo que equivale a complejos de grandes dimensiones (promedio de 130 ha y 400 viviendas). En Sevilla y Valencia, el tamaño medio es sensiblemente menor (35 y 53 ha y 150 y 279 viviendas respectivamente). Por su parte, Wehrhahn y Raposo ${ }^{61}$ constatan, sin llegar a cuantificarlos, el relativo éxito en Madrid de los denominados condominios o pequeños complejos cerrados. En Sevilla y Valencia se han reconocido tan solo 4 y 3 casos, si bien

60 Canosa, 2002.

61 Wehrhahn y Raposo, 2006; Raposo, 2006. dos de ellos (urbs. Aljamar y Mas de Camarena) conforman en realidad un conglomerado de barrios de este tipo, y en su conjunto son los mayores cerramientos en sus respectivos ámbitos. Estos mismos autores dimensionan el fenómeno en Lisboa, donde contabilizan 97 gated communities y más de 10.000 viviendas, y señalan una notable diversidad morfológica (72 pequeños complejos de apartamentos, 18 urbanizaciones medianas de vivienda unifamiliar y 7 macrourbanizaciones). La comparación con las cifras de otros contextos ayuda a calibrar, a grandes rasgos, el estadio de este fenómeno en España ${ }^{62}$ : por ejemplo, el Área Metropolitana de Buenos Aires (350 casos, 29.000 hectáreas y 84.000 parcelas), el sur de California (219 casos y 80.000 viviendas), Lima (300 casos), Mendoza (70), Quito (27) o Montevideo (10). La mayoría de estos estudios revelan la coexistencia de las grandes urbanizaciones de localización periférica con la proliferación de pequeños barrios cerrados insertos en la trama urbana consolidada (en Santiago de Chile y Valparaíso se contabilizan 763 y 293 respectivamente).

Las cifras que contemplamos en esta investigación, en comparación con los datos anteriores, informan de un fenómeno incipiente en nuestros ámbitos de estudio — si bien deben manejarse con cautela por la disparidad de criterios-. Por su parte, si se

62 A partir de Le Goix, 2007; Thuillier, 2005; Vidal Kooppmann, 2008 y Roitman y Giglio, 2010. 
relativizan los números según el peso demográfico de ambas urbes, sí puede hablarse de cierto desarrollo de estas fórmulas de segregación urbana, especialmente en Sevilla. De otro lado, esta investigación pone de manifiesto que en España estamos, de momento, ante un fenómeno principalmente periurbano, en contraste con otros indicios de comunidades cerradas en el corazón de algunas ciudades europeas (Londres, Liverpool, París, Estambul) ${ }^{63}$.

En esta investigación también se ha podido reconocer la existencia de tipologías particulares, adaptadas a las circunstancias geográficas propias de los dos ámbitos de estudio, que contrastan con los casos más ajustados a las definiciones canónicas de urbanización cerrada. Así, en Sevilla se distingue un modelo particular de cerramiento urbano, predominante en los entornos rurales, donde la mezcla de atributos propios del medio agrícola y elementos de influencia urbana y periurbana configuran un paisaje residencial singular. La restricción en este tipo de urbanizaciones suele ser de tipo pasivo (sin la presencia de personal de seguridad), sustentado en cancelas en los accesos y restricciones indicativas. En muchas de ellas la condición de cerradas es irregular, pues mantienen un régimen de cerramiento distinto de día que de noche. La controvertida situación de limbo

63 Webster, 2001; Blandy, 2007; Raposo, 2007; Gülümser y BaycanLevent, 2009. legal en la que por lo general se encuentran estas urbanizaciones también afecta a la desregulación de sus cerramientos. Aunque presente en todo este ámbito, esta tipología es predominante en el sector de Los Alcores.

Por su parte, en Valencia el modelo suburbano de urbanización cerrada al uso se alterna con soluciones más singulares estrechamente vinculadas al fenómeno turístico litoral. El marcado régimen de ocupación estival de estas áreas residenciales conduce a un cerramiento disimétrico entre el verano y el invierno. Así, la vigilancia y el reforzamiento de las medidas disuasorias se intensifican en temporada alta.

La constatación de estas realidades urbanas obliga a matizar el uso generalizado del concepto de urbanización cerrada. Retomando el argumento de Roitman ${ }^{64}$ sobre la necesidad de un aval legislativo, en los casos estudiados las urbanizaciones cerradas poseen de un encaje legal ambiguo y poco preciso, y se han acabado por aceptar institucionalmente por la vía de los hechos consumados. En este sentido, resulta oportuno recurrir al concepto de pseudo-gated community — que ya introdujeran Wehrhahn y Raposo ${ }^{65}$ para el caso de Madrid-o a la noción más flexible de cerramiento urbano. En Sevilla tanto como en Valencia, las fórmulas de cerramiento sugieren que nos encontramos ante un

64 Roitman, 2004.

65 Wehrhahn y Raposo, 2006. 
espacio cerrado y privado de facto, ya que jurídicamente no hay propiedad privada, pero se cohíbe el tránsito generalizado y se procura la idea virtual de un usufructo exclusivo.

Todo lo anterior da pie a diversas consideraciones. Ante la evidente consolidación del fenómeno de la ciudad enclaustrada y privatizada, que adquiere forma concreta en la fórmula urbanística de las urbanizaciones cerradas, la implicación de las administraciones públicas resulta necesaria. Como tuteladores de la cosa pública urbana, ayuntamientos, entidades municipales y otros organismos competentes deben adoptar una política definida que resuelva el estado de indeterminación jurídica y que refuerce el papel político de lo público en la gestión de la ciudad. A este respecto existen voces acreditadas que han manifestado cierta suspicacias para con el modelo urbanístico propio de las comunidades cerradas. Desde el Programa de Naciones Unidas para los Asentamientos Humanos (UN-Habitat), por medio de su director ejecutivo ${ }^{66}$, se ha puesto el acento en la creciente desigualdad y desasosiego que subyacen tras estos complejos residenciales, vistos como una amenaza para la vida pública y democrática de las ciudades. Este mismo organismo plantea estrategias de diseño y planificación urbanas, tales como la mejora de la seguridad y la reducción del crimen, a partir

66 Declaraciones de Joan Clos, director ejecutivo de UN-Habitat, en The Guardian (2/5/2014). de tratamientos que refuerzan el sentido colectivo del espacio público por antonomasia: la calle y la plaza $^{67}$.

Para finalizar proponemos una serie de perspectivas futuras de estudio. En primer lugar podría profundizarse en las razones que explican el relativo éxito de estas fórmulas de exclusión urbana desde la perspectiva de la demanda, para lo cual sería necesario realizar un detenido análisis de carácter socioeconómico. En segundo lugar, y relacionado con el anterior, sería de interés comprobar el vínculo entre el éxito de estas fórmulas de autosegregación con la creciente desigualdad social en España, enfatizando la conexión entre la polarización social y el éxito en la venta de estos productos inmobiliarios. Una tercera y última perspectiva sería hacer extensible el estudio a determinados sectores del litoral español, donde se entraría a valorar la correlación de estas realidades con el turismo y el residencialismo de las comunidades extranjeras.

67 UN-Habitat, 2013. 


\section{ANEXO: URBANIZACIONES CERRADAS Y OTROS CERRAMIENTOS URBANOS EN LOS ÁMBITOS DE ESTUDIO: CARACTERÍSTICAS BÁSICAS.}

\begin{tabular}{|c|c|c|c|c|c|c|c|c|}
\hline 응 & 으을 & 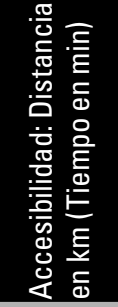 & 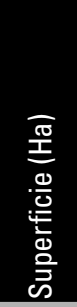 & $\frac{\substack{\frac{\pi}{0} \\
\frac{C}{0}}}{\sum}$ & 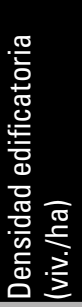 & 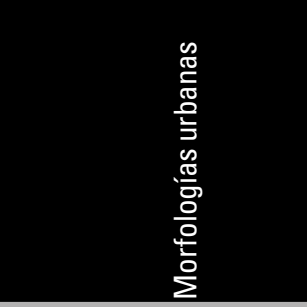 & $\begin{array}{l}\text { 은 } \\
\text { 을 } \\
\text { 드 }\end{array}$ & 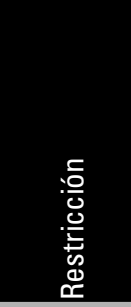 \\
\hline \multicolumn{9}{|c|}{ AGLOMERACION URBANA DE SEVILLA } \\
\hline Aljamar & Tomares & $6,6(11)$ & 43,6 & 674 & 15,5 & U. semiexentos pareados & Suburbano & Total \\
\hline Pradollano & Carmona & $23,8(30)$ & 115,3 & 455 & 3,9 & U.Ex. con jardín y/o huerta & Rural & Total \\
\hline Real Club Sevilla G & Alcalá de G. & $7,8(16)$ & 100,2 & 367 & 3,7 & Vivienda adosada y U.Ex. & Suburbano & De control \\
\hline Frutales del Alcor & Carmona & $30,2(42)$ & 86,2 & 336 & 3,9 & U.Ex. con jardín y/o huerta & Rural & Indicativa \\
\hline Hato Verde Golf & Guillena & $25,8(22)$ & 100,2 & 295 & 2,9 & Vivienda adosada y U.Ex. & Suburbano & De control \\
\hline Los Jinetes & Carmona & $31,6(32)$ & 85,2 & 292 & 3,4 & U.Ex. con jardín y/o huerta & Rural & Total \\
\hline Los Nietos & Carmona & $22,8(30)$ & 59,7 & 289 & 4,8 & U.Ex. con jardín y/o huerta & Rural & Indicativa \\
\hline Las Pilas & Valencina & $10(18)$ & 42,4 & 276 & 6,5 & U.Ex. con jardín & Suburbano & De control \\
\hline Zaudin Golf & Bormujos & $7,7(14)$ & 98,7 & 270 & 2,7 & U.Ex. con jardín & Suburbano & De control \\
\hline La Juliana & Bollullos de la M. & $18,2(20)$ & 68,3 & 247 & 3,6 & U.Ex. con jardín & Suburbano & Total \\
\hline Torrequinto & Alcalá de G. & $10,7(20)$ & 40,3 & 231 & 5,7 & U.Ex. con jardín & Suburbano & Total \\
\hline Pino Grande & Carmona & $17,2(21)$ & 31,0 & 230 & 7,4 & U.Ex. con jardín y/o huerta & Suburbano & De control \\
\hline El Torreón & Mairena del Alcor & $20,3(29)$ & 26,8 & 218 & 8,1 & U.Ex. con jardín & Suburbano & Total \\
\hline Las Monjas & Carmona & $24,2(35)$ & 61,4 & 190 & 3,1 & U.Ex. con jardín y/o huerta & Rural & Indicativa \\
\hline Camposol & Carmona & $19,8(28)$ & 54,6 & 190 & 3,5 & U.Ex. con jardín y/o huerta & Rural & Indicativa \\
\hline Urb Parque Real & Gines & $8,9(13)$ & 6,9 & 189 & 27,5 & U. semiexentos pareados & Suburbano & Total \\
\hline Los Naranjos & Carmona & $19(25)$ & 114,4 & 188 & 1,6 & U.Ex. con jardín y/o huerta & Rural & Indicativa \\
\hline La Cierva & Carmona & $25(30)$ & 21,2 & 185 & 8,7 & U.Ex. con jardín & Suburbano & Total \\
\hline La Galbana & Alcalá de G. & $18,3(23)$ & 49,7 & 138 & 2,8 & U.Ex. con jardín y/o huerta & Rural & Indicativa \\
\hline Las Minas & Aznalcázar & $27,1(29)$ & 41,2 & 130 & 3,2 & U.Ex. y adosados & Suburbano & De control \\
\hline Las Almas & Carmona & $19(25)$ & 114,4 & 128 & 1,1 & U.Ex. con jardín y/o huerta & Rural & Indicativa \\
\hline Cerros del Alcor & Carmona & $27,3(36)$ & 39,0 & 127 & 3,3 & U.Ex. con jardín y/o huerta & Rural & Indicativa \\
\hline Matallana & Carmona & $25,3(30)$ & 12,1 & 124 & 10,2 & U.Ex. con jardín y/o huerta & Rural & Total \\
\hline Alegría & Alcalá de G. & $14,9(21)$ & 16,7 & 122 & 7,3 & U.Ex. con jardín y/o huerta & Rural & De control \\
\hline Canteras-Colina Blanca & Camas & $4,7(8)$ & 24,1 & 121 & 5,0 & U.Ex. con jardín & Suburbano & Total \\
\hline Matagrande & Alcalá de G. & $17,7(31)$ & 18,3 & 121 & 6,6 & U.Ex. con jardín y/o huerta & Rural & Total \\
\hline Alquería Almanzor & Espartinas & $8,9(15)$ & 11,0 & 120 & 10,9 & U.Ex. con jardín & Suburbano & De control \\
\hline San Fernando & Mairena del Alcor & $20,9(31)$ & 16,9 & 105 & 6,2 & U.Ex. con jardín & Suburbano & Indicativa \\
\hline Los Bancales & El Viso del Alcor & $25,8(32)$ & 46,4 & 103 & 2,2 & U.Ex. con jardín y/o huerta & Rural & Total \\
\hline Ventanal Bajo & Carmona & $30,2(30)$ & 31,7 & 97 & 3,1 & U.Ex. con jardín y/o huerta & Suburbano & Total \\
\hline Azucena & Mairena del Alcor & $20,2(29)$ & 5,6 & 95 & 17,0 & U. semiexentos pareados & Suburbano & Total \\
\hline
\end{tabular}




\begin{tabular}{|c|c|c|c|c|c|c|c|c|}
\hline $\begin{array}{l}\text { 은 } \\
\text { 틍 }\end{array}$ & $\frac{\text { 음을 }}{\frac{0}{5}}$ & 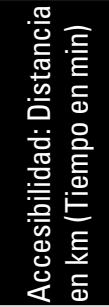 & 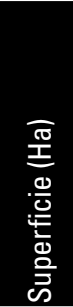 & 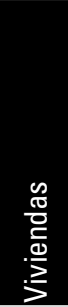 & 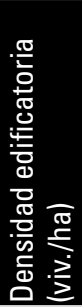 & 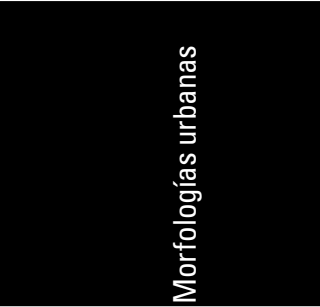 & $\begin{array}{l}\text { 은 } \\
\text { 등 } \\
\text { 륻 }\end{array}$ & 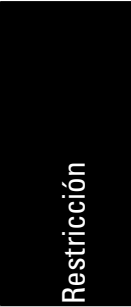 \\
\hline La Hacienda & Dos Hermanas & $14,5(19)$ & 17,5 & 90 & 5,2 & U.Ex. con jardín & Suburbano & De control \\
\hline Las Tres Palmeras & Carmona & $29,9(31)$ & 22,2 & 90 & 4,1 & U.Ex. con jardín y/o huerta & Rural & Total \\
\hline Villa Europa & Espartinas & $9,4(11)$ & 7,8 & 81 & 10,4 & U.Ex. con jardín & Suburbano & De control \\
\hline Sra. de la Salud & Mairena del Alcor & $21,2(31)$ & 13,0 & 80 & 6,1 & U.Ex. con jardín & Suburbano & Total \\
\hline Matachica & Alcalá de G. & $17,6(30)$ & 16,3 & 78 & 4,8 & U.Ex. con jardín y/o huerta & Rural & Indicativa \\
\hline Villares Altos & Tomares & $3,9(6)$ & 16,2 & 76 & 4,7 & U.Ex. con jardín & Suburbano & De control \\
\hline Los Claveles & Mairena del Alcor & $19,7(31)$ & 13,6 & 70 & 5,1 & U.Ex. con jardín & Suburbano & Total \\
\hline El Magistrado & Alcalá de G. & $14,4(23)$ & 9,1 & 70 & 7,7 & U.Ex. con jardín y/o huerta & Rural & Total \\
\hline Torrelaguna & Carmona & $27,6(32)$ & 13,0 & 69 & 5,3 & U.Ex. con jardín y/o huerta & Rural & Indicativa \\
\hline El Campillo & Mairena del Alcor & $20,7(33)$ & 9,7 & 66 & 6,8 & U.Ex. con jardín & Suburbano & Total \\
\hline El Grullo-El Nevero & Alcalá de G. & $17,7(28)$ & 17,3 & 65 & 3,7 & U.Ex. con jardín y/o huerta & Rural & Indicativa \\
\hline Entremontes & Guillena & $35,3(22)$ & 26,3 & 60 & 2,3 & U.Ex. con jardín y/o huerta & Rural & Total \\
\hline San Blas & Mairena del Alcor & $20,6(32)$ & 16,3 & 58 & 3,6 & U.Ex. con jardín y/o huerta & Rural & Indicativa \\
\hline Los Sajardines & Sanlúcar la Mayor & $19,4(16)$ & 11,2 & 54 & 4,8 & U.Ex. con jardín & Suburbano & Indicativa \\
\hline Las Nieves & Guillena & $35,8(22)$ & 12,3 & 52 & 4,2 & U.Ex. con jardín y/o huerta & Rural & Total \\
\hline Huerta del Soldado & Carmona & $33,5(41)$ & 23,0 & 52 & 2,3 & U.Ex. con jardín y/o huerta & Rural & Indicativa \\
\hline El Galope & La Puebla del Río & $25,7(32)$ & 11,1 & 48 & 4,3 & U.Ex. con jardín y/o huerta & Rural & Total \\
\hline Los Arrayanes & La Puebla del Río & $23,6(36)$ & 10,8 & 43 & 4,0 & U.Ex. con jardín y/o huerta & Rural & Total \\
\hline Virgen de Araceli & Carmona & $28,6(36)$ & 8,7 & 27 & 3,1 & U.Ex. con jardín y/o huerta & Rural & Total \\
\hline Pino de Santa Clara & Sevilla & $6,2(10)$ & 1,7 & 23 & 13,5 & U.Ex. con jardín & Suburbano & Total \\
\hline Balcón de los Alcores & El Viso del Alcor & $27,1(38)$ & 2,6 & 18 & 7,0 & U.Ex. con jardín & Suburbano & Indicativa \\
\hline La Gacela & Carmona & $24,3(30)$ & 10,5 & 9 & 0,9 & U.Ex. con jardín y/o huerta & Rural & Total \\
\hline Ciudad Expo & Mairena del Alj. & $7,2(13)$ & 16,9 & sd & sd & Plurifamiliar de baja altura & Suburbano & Indicativa \\
\hline \multicolumn{9}{|c|}{ AGLOMERACIÓN URBANA DE VALENCIA } \\
\hline Mas de Camarena & Betera & $14,5(21)$ & 69,4 & 1248 & 18,0 & U.Ex. con jardín y adosados & Suburbano & Total \\
\hline San Cristóbal & Alberic & $47(40)$ & 252,2 & 640 & 2,5 & U.Ex. con jardín y/o huerta & Rural & De control \\
\hline El Bosque & Chiva & $32(28)$ & 175,4 & 554 & 3,2 & U.Ex. con jardín y adosados & Suburbano & De control \\
\hline Masia de Traver & Riba Roja de Turia & $17,9(27)$ & 54,5 & 542 & 10,0 & U.Ex. con jardín & Suburbano & De control \\
\hline Tancat el Alter & Picassent & $18,2(32)$ & 78,1 & 318 & 4,1 & U.Ex. con jardín & Suburbano & De control \\
\hline Olimar & Chiva & $22,5(21)$ & 48,2 & 306 & 6,3 & U.Ex. con jardín & Suburbano & De control \\
\hline San Antonio & San Antonio & $17,4(24)$ & 38,5 & 193 & 5,0 & U.Ex. con jardín & Suburbano & De control \\
\hline Serramar & Picassent & $26,3(33)$ & 42,7 & 193 & 4,5 & U.Ex. con jardín & Suburbano & De control \\
\hline Santa Bárbara & Rocafort-Valencia & $10,2(23)$ & 75,5 & 169 & 2,2 & $\begin{array}{l}\text { U.Ex. con jardín y } \\
\text { plurifamiliares }\end{array}$ & Suburbano & De control \\
\hline Cap Blanc & Cullera & $39,3(49)$ & 19,3 & 162 & 8,4 & $\begin{array}{l}\text { U.Ex., adosados y } \\
\text { plurifamiliares }\end{array}$ & $\begin{array}{l}\text { Turístico- } \\
\text { Litoral }\end{array}$ & Indicativa \\
\hline
\end{tabular}




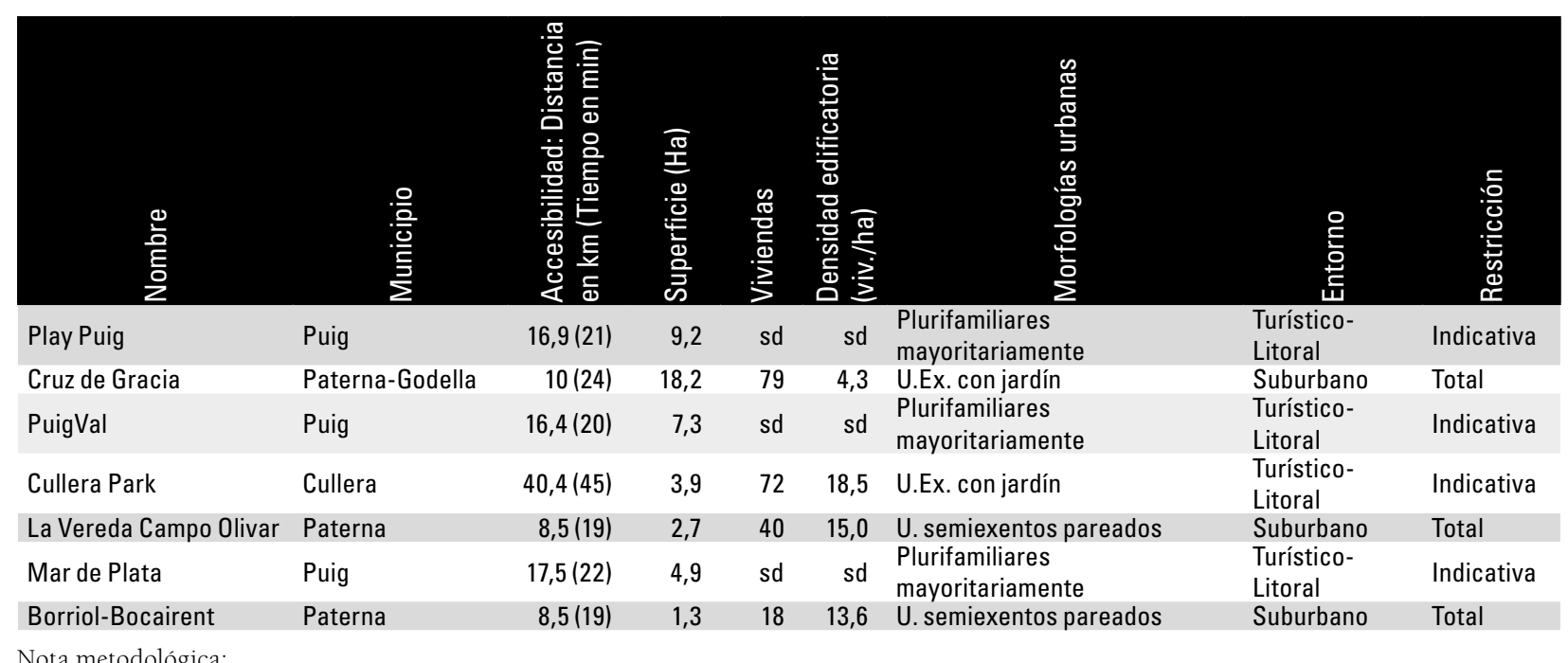

Nota metodológica:

- Los valores de accesibilidad potencial (distancia y tiempo) se han calculado a partir de la ruta óptima más corta en base a la red viaria del proyecto Cartociudad (Instituto Geográfico Nacional < http://www.cartociudad.es/portal/>) mediante un análisis de redes (software QGis).

- El dato del número de viviendas ha sido obtenido partiendo de la cartografía básica del Catastro (Dirección General del Catastro <http://www.

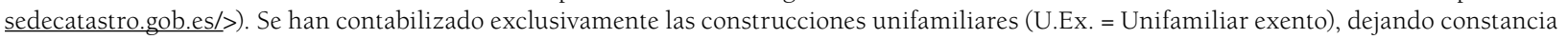
de la existencia de formatos plurifamiliares en la descripción de morfologías urbanas ( $s d=\sin$ datos). 


\section{Bibliografía}

AMÉNDOLA, Giamenico. La ciudad postmoderna. Madrid, Celeste. 2000. 379 p. ISBN 978-8482112404.

ARROYO LÓPEZ-SORO, José. Urbanizaciones privadas, conjuntos y complejos inmobiliarios y aprovechamiento por turno de bienes inmuebles de uso turístico. Estudio jurídico práctico de sus principales problemas: criterios jurisprudenciales actuales. Madrid, Dykinson. 1999. 608 p. ISBN 84-81552186.

ATKINSON, Rowland y BLANDY, Sarah. International perspectives on the new enclavism and the rise of gated communities. En: Gated Communities. London, Routledge. 2007. p. 7-16. ISBN 978-0415463799.

BAGAEEN, Samer. Gated urban life versus kinship and social solidarity in the Middle East. En: Gated communities: social sustainability in contemporary and historical gated developments. Londres, Earthscan. 2010. p. 15-25. ISBN 978-1844075195.

BAUMAN, Zygmunt. Confianza y temor en la ciudad. Vivir con extranjeros. Barcelona, Arcadia. 2006. 75 p. ISBN 978-8493409630.

BLAKELY, Edward James y SNYDER, Mary Gail. Fortress America. Washington D.C., Brookings Institution and the Lincoln Institute of Land Policy. 1997. ISBN 978-0815710028.

BLANDY, Sarah. Gated communities in England as a response to crime and disorder: context, effectiveness and implications. [En línea]. People, Place $\mathcal{E}$ Policy Online. 1(2): 47-54, 2007. ISSN 1753-8041.
DOI 10.3351/ppp.0001.0002.0001. Disponible en: http://extra.shu.ac.uk/ppp-online/gated-communities-in-england-as-a-response-to-crime-anddisorder-context-effectiveness-and-implications/.

BLANQUER CRIADO, David. Turismo residencial y urbanizaciones privadas: los servicios públicos de prestación obligatoria y alternativas a su incumplimiento por el Ayuntamiento. En: Ordenación y gestión del territorio turístico. Valencia, Tirant lo Blanc. 2002. p. 843-950. ISBN 84-84425363.

BOAL, Frederick Urban ethnic segregation and the scenarios spectrum. [En línea]. En: International Seminar on Segregation in the City (2001, Cambridge, Mass). Cambridge, Mass, Estados Unidos, Lincoln Institute of Land Policy. 2001. Disponible en: https://www. lincolninst.edu/pubs/dl/596_boal.pdf.

BRUNN, S. Gated minds and gated lives at worlds of exclusion and fear. Geojournal. 66(1-2): 5-13, 2006. ISSN 0343-2521. DOI 10.1007/s10708-006-9012-5.

CANOSA ZAMORA, Elia. Urbanizaciones cerradas en espacios metropolitanos: Ínsulas para unos pocos. En: La vivienda y el espacio residencial en las áreas metropolitanas. Sevilla, Junta de Andalucía. 2007. p. 151-174. ISBN 978-8461192809.

--- Las urbanizaciones cerradas de lujo en Madrid: una nueva fórmula de propiedad y de organización territorial. Ciudad y Territorio: Estudios Territoriales. (133-134): 545-564, 2002. ISSN 1133-4762.

CARAVACA BARROSO, Inmaculada y GARCÍA GARCÍA, Antonio. El debate sobre los territorios inteligentes: el caso del área metropolitana de Sevilla. 
Eure, Revista Latinoamericana de Estudios UrbanoRegionales. 35(105): 23-45, 2009. ISSN 02507161. DOI 10.4067/S0250-71612009000200002.

CORTÉS, José Miguel. La ciudad cautiva. Control y vigilancia en el espacio urbano. Madrid, Akal. 2010. 224 p. ISBN 978-844602780.

DAVIS, Mike. Más allá de Blade Runner. Control urbano: la ecología del miedo. Barcelona, Virus. 2001. 71 p. ISBN 978-8488455895.

--- City of quartz: excavating the future in Los Angeles. Londres, Verso. 1990. 462 p. ISBN 978-1844675685.

DELGADO BUJALANCE, Buenaventura y GARCÍA GARCÍA, Antonio. Una aproximación a los nuevos paisajes de la metápolis en Andalucía. Scripta Nova. 13(297), 2009. ISSN 1138-9788.

ELLIN, Nan. Postmodern urbanism. Nueva York, Princeton Architectural Press. 1999. 368 p. ISBN 978-1568981352.

--- Shelter from the storm or form follows fear and vice versa. En: Architecture of fear. Nueva York, Princeton Architectural Press. 1997. p. 13-46. ISBN 978-1568980829.

EUROSTAT. European Union Stadistics on Income and Living Conditions: Gini Coefficient of equivalised disposable income. [En línea]. 2014. [Fecha de consulta: 11 de junio de 2014]. Disponible en: http://epp.eurostat.ec.europa.eu/statistics_explained/index.php/Income_inequality_statistics.

FERIA TORIBIO, José María. Un ensayo metodológico de definición de las áreas metropolitanas en
España a partir de la variable residencia-trabajo. Investigaciones Geográficas. (46): 49-68, 2008. ISSN 1989-9890.

FLUSTY, Steven. Building paranoia. En: Architecture of fear. Nueva York, Princeton Architectural Press. 1997. p. 47-60. ISBN 978-1568981352.

FRANTZ, Klaus. Private gated neighborhoods - a progressive trend in US-urban development. En: Private cities: global and local perspectives. Nueva York, Routledge. 2006. p. 64-74. ISBN 978-0415341707.

FUNDACIÓN 1 de Mayo. La situación social en España. Informe anual de política social. [En línea]. Informes. (76), 2014. [Fecha de consulta: 6 junio 2014]. Disponible en: http://www.lmayo.ccoo.es/nova/ files/1018/Informe76.pdf.

GENIS, Serife. Producing elite localities: the rise of gated communities in Istanbul. Urban Studies. 44(4): 771-798, 2011. ISSN 0042-0980. DOI 10.1080/00420980601185684

GLASZE, Georg, ed.; WEBSTER, Chris, ed. y FRANTZ, Klaus, ed. Private cities: global and local perspectives. Nueva York, Routledge. 2006. P. 167-186. ISBN 978-0415341707.

GRUPO Aduar. Diccionario de geografía urbana, urbanismo y ordenación del territorio. Barcelona, Ariel. 2000. 407 p. ISBN 84-344-0519-9

GÜLÜMSER, Aliye Ahu y BAYCAN-LEVENT, Tüzin. Through the sky: vertical gated developments in Istanbul. The Urban Reinventors. 3(9): 1-18, 2009. 
GUZEY, Özlem. Neoliberal urbanism restructuring the city of Ankara: gated communities as a new life style in a suburban settlement. Cities. 36: 93-103, 2014. ISSN 0264-2751. DOI 10.1016/j.cities.2013.10.005.

INSTITUTO Nacional de Estadística. Censos de población y Viviendas 2011. [En linea]. INE. 2011. Disponible en http://www.ine.es/censos2011_datos/ cen11_datos_inicio.htm.

JUARISTI LINACERO, Joseba. El aire de la ciudad postmoderna: identidad, espacio público, cultura y miedo. En: La ciudad y el miedo (VII Coloquio de Geografía Urbana). Gerona, Universidad de Gerona. 2005. P. 269-288. ISBN 84-8458-214-0.

JUDT, Tony. Algo va mal. Madrid, Taurus. 2010. 256 p. ISBN 978-8430607969.

JÜRGENS, Ulrich y GNAD, Martin. Gated communities in South Africa-experiences from Johannesburg. Environment and Planning B: Planning and Design. 29(3): 337-353, 2002. ISSN 0265-8135. DOI $10.1068 / \mathrm{b} 2756$.

KOHN, Margaret. Brave new neighborhoods. The privatization of public space. Londres, Routledge. 2004. 240 p. ISBN 978-0415944632.

LE GOIX, Renaud. Gated communities: sprawl and social segregation in Southern California. En: ATKINSON, Roland, ed. y BLANDY, Sarah, ed. Gated communities. Nueva York, Routledge. 2007. p. 131-151. ISBN 978-0415463799.

LÓPEZ LEVI, Liliana y RODRÍGUEZ CHUMILLAS, Isabel. Miedo y consumo: El encerramiento habitacional

ARTíCULO:Ciudad segregada en España: urbanizaciones cerradas en Valencia y Sevilla/ Arsenio Villar Lama y Miguel García Martín en México y Madrid. Urban perspectives. (5): 2132, 2004. ISSN 1695-534X.

LOW, Setha. Behind the gates: life, security, and the pursuit of happiness in Fortress America. Nueva York, Routledge. 2003. 288 p. ISBN 978-0415950411.

--- The edge and the center: gated communities and the discourse of urban fear. American Anthropologist. 103(1): 45-58, 2001. ISSN: 1548-1433. DOI 10.1525/aa.2001.103.1.45.

MALIZIA, Matilde. Enfoque teórico y conceptual para el estudio de las urbanizaciones cerradas. [En línea]. Andes. 22(2), diciembre 2011. ISSN 1668-8090. [Fecha de consulta: 23 marzo 2015]. Disponible en: http://www.scielo.org.ar/scielo.php?script=sci arttext\&pid=S1668-80902011000200005\&lng= es\&nrm=iso

MUMFORD, Lewis. The city in history: its origins, its transformations, and its prospects. Nueva York, Harcourt, Brace y World. 1961. 657 p. ISBN 978-0156180351.

O’NEILL, Maria Monica Vieira Caetano. Condominos exclusivos: un estudo de caso. Revista Brasileira de Geografia. 48(1): 63-81, enero-marzo1986. ISSN 0034-723X.

PLÁ, Rodrigo. (Dir.). La zona. México, Coproducción México-España Morena Films. 2007

POLANSKA, Dominika. The emergence of gated communities in post-communist urban context: and the reasons for their increasing popularity. Journal of Housing and the Built Environment. 25(3): 295-312, 2011. ISSN 1566-4910.

revista invi № 86 / May 2016 / Volume № 31: 145-177 175 
PRADA TRIG0, José. Privatización del espacio en los nuevos contextos urbanos y socioculturales: El fenómeno de las gated communities. Lurralde, Investigación y Espacio. (34): 219-234, 2011. ISSN 0211-5891.

RAPOSO, Rita. Looking backward: Lisbon, 2007 - California, 1970's - Manchester, 1837 - London, 1726; or a cultural historical analysis of gated communities. [En línea]. 4th International conference private urban gobernance $\&$ gated communities, París, 5-8 de junio de 2007. [Fecha de consulta: 23 de marzo de 2015]. Disponible en: http://www.staff.uni-mainz.de/glasze/Abstracts_ Papers_Paris_2007/Raposo.pdf.

--- Gated communities, commodification and aestheticization: the case of the Lisbon metropolitan area. GeoJournal. 66(1): 43-56, 2006. ISSN 0343-2521. DOI 10.1007/s10708-006-9015-2

ROITMAN, Sonia y GIGLI0, Mónica Adriana. Latin American gated communities: the latest symbol of historic social segregation. En: BAGAEEN, Samer, ed. y UDUKU, Ola, ed. Gated communities: social sustainability in contemporary and historical gated developments. Londres y Washington, Earthscan. 2010. p. 63-78. ISBN 978-1849774772.

ROITMAN, Sonia. Urbanizaciones cerradas: estado de la cuestión hoy y propuesta teórica. Revista de Geografía Norte Grande. (32): 5-19, 2004. ISSN 0718-3402.

SALCED0, Rodrigo. Relaciones entre residentes de comunidades ideológicas y pobladores de vivienda social. En: HIDALGO, Rodrigo, ed.; TRUMPER Ricardo, ed. y BORSDORF, Alex, ed. Transformaciones metropolitanas y procesos territoriales. Lecturas del nuevo dibujo de la ciudad latinoamericana. Santiago de Chile, Pontificia Universidad Católica de Chile. 2005. p. 161-172. ISBN 956-1408236.

SMIGIEL, Christian. The production of segregated urban landscapes: A critical analysis of gated communities in Sofia. Cities. 35: 125-135, 2013. ISSN 0264-2751. DOI 10.1016/j.cities.2013.06.008.

SORKIN, Michael. Nos vemos en Disneylandia. En: SORKIN, Michael, ed. Variaciones sobre un parque temático: la nueva ciudad americana y el fin del espacio público. Barcelona, Gustavo Gili. 2004. p. 231-258. ISBN 978-8425219696.

STOYANOV, Petar y FRANTZ, Klaus. Gated communities in Bulgaria: Interpreting a new trend in post-communist urban development. GeoJournal. 66(1): 57-63, junio de 2006. ISSN 0343-2521. DOI 10.1007/s10708-006-9016-1.

THUILLIER, Guy. Gated communities in the metropolitan area of Buenos Aires. Housing Studies. 20(2): 255-271, 2005. ISSN 0267-3037. DOI $10.1080 / 026730303042000331763$.

UDUKU, Ola y BAGAEEN, Samer. Afterword. En: BAGAEEN, Samer, ed. y UDUKU, Ola, ed. Gated communities: social sustainability in contemporary and historical gated developments. Londres, Earthscan. 2010. p. 131-133. ISBN 978-1849774772.

UN-Habitat. Urban planning for city leaders. 2a. ed. Nairobi. UN Habitat. 2013. 176 p. ISBN 978-92-1-132505-8

VALERA Pertegàs, Sergi. Conflicto y miedo ante un nuevo espacio público urbano. En: FERNÁNDEZ 
RAMÍREZ, Baltasar, ed. y VIDAL MORANTA, Tomeu, ed. Psicología de la ciudad. Debate sobre el espacio urbano. Barcelona, Editorial UOC. 2008. p. 149-162. ISBN 978-8497883566.

VIDAL-KOOPPMANN, Sonia. Mutaciones metropolitanas: de la construcción de barrios cerrados a la creación de ciudades privadas: balance de una década de urbanización privada en la región metropolitana de Buenos Aires. [En línea]. Scripta Nova: Revista Electrónica de Geografía y Ciencias Sociales. 12(270[111]), 2008. ISSN 1138-9788. [Fecha de consulta: 23 marzo 2015]. Disponible en: http:// www.ub.edu/geocrit/sn/sn-270/sn-270-111.htm.

--- Segregación residencial y apropiación del espacio: La migración hacia las urbanizaciones cerradas del área metropolitana de Buenos Aires (Argentina). [En línea]. Scripta Nova: Revista Electrónica de Geografía y Ciencias Sociales. 94(70), 2001. ISSN 1138-9788. [Fecha de consulta: 23 de marzo de 2015]. Disponible en: http://www.ub.edu/geocrit/ sn-94-70.htm.

WEBSTER, Chris. Gated cities of tomorrow. The Town Planning Review. 72(2): 149-170, abril de 2001. ISSN 0041-0020.

WEHRHAHN, Rainer y RAPOSO, Rita. The rise of gated residential neighbourhoods in Portugal and Spain: Lisbon and Madrid. En: GLASZE, Georg, ed.; WEBSTER, Chris, ed. y FRANTZ, Klaus ed. Private cities: global and local perspectives. Nueva York, Routledge. 2006. P. 167-186. ISBN 978-0415341707.

WEHRHAHN, Rainer. Gated communities in Madrid: Zur Funktion von Mauern im europaischen
Kontext. Geographica Helvetica. 58(4): 302-313, 2003. ISSN 0016-7312.

\section{Normativa consultada:}

DECRETO 267/2009, de 9 de junio, por el que se aprueba el Plan de Ordenación del Territorio de la Aglomeración Urbana de Sevilla y se crea su Comisión de Seguimiento. Boletín Oficial de la Junta de Andalucía, 9 de julio de 2009, número 132, p. 114.

DECRET0 60/2010, de 16 de marzo, por el que se aprueba el Reglamento de Disciplina Urbanística de la Comunidad Autónoma de Andalucía. Boletín Oficial de la Junta de Andalucía, 7 de abril de 2010, número 66, p. 12.

LEY 49/1960 sobre Propiedad Horizontal. Boletín Oficial del Estado, 23 de julio de 1960, número 176, p. 10299.

LEY 7/2002, de 17 de diciembre, de Ordenación Urbanística de Andalucía. Boletín Oficial de la Junta de Andalucía, 31 de diciembre de 2002, número 154, p. 25.084.

LEY 8/1999 de Reforma de la Ley 49/1960 sobre Propiedad Horizontal. Boletín Oficial del Estado, 6 de abril de 1999, número 84, p. 13104.

LEY 8/2007 de Suelo. Boletín Oficial del Estado, 29 de mayo de 2007, número 128, p. 23.266. 
